FEDERAL RESERVE BANK OF SAN FRANCISCO

WORKING PAPER SERIES

\title{
Putting the Brakes on Sudden Stops: The Financial Frictions-Moral Hazard Tradeoff of Asset Price Guarantees
}

\author{
Enrique G. Mendoza \\ University of Maryland \\ Ceyhun Bora Durdu \\ University of Maryland
}

September 2004

Working Paper 2004-33

http://www.frbsf.org/publications/economics/papers/2004/wp04-33bk.pdf

This paper was presented at the conference on "Emerging Markets and Macroeconomic Volatility: Lessons from a Decade of Financial Debacles" cosponsored by the Center for Pacific Basin Studies of the Federal Reserve Bank of San Francisco and the Center for International Economics at the University of Maryland and held at the FRBSF on June 4-5 2004. The views in this paper are solely the responsibility of the authors and should not be interpreted as reflecting the views of the Federal Reserve Bank of San Francisco or the Board of Governors of the Federal Reserve System 
Draft: September 10, 2004

\title{
Putting the Brakes on Sudden Stops: The Financial Frictions-Moral Hazard Tradeoff of Asset Price Guarantees
}

\author{
by
}

\author{
Enrique G. Mendoza \\ Department of Economics \\ University of Maryland and NBER \\ College Park, MD 20742
}

\author{
Ceyhun Bora Durdu \\ Department of Economics \\ University of Maryland \\ College Park, MD 20742
}

The hypothesis that Sudden Stops to capital inflows in emerging economies may be caused by global capital market frictions, such as collateral constraints and trading costs, suggests that Sudden Stops could be prevented by offering price guarantees on the emerging-markets asset class. Providing these guarantees is a risky endeavor, however, because they introduce a moral-hazard-like incentive similar to those that are also viewed as a cause of emerging markets crises. This paper studies this financial frictions-moral hazard tradeoff using an equilibrium asset-pricing model in which margin constraints, trading costs, and ex-ante price guarantees interact in the determination of asset prices and macroeconomic dynamics. In the absence of guarantees, margin calls and trading costs create distortions that produce Sudden Stops driven by occasionally binding credit constraints and Irving Fisher's debt-deflation mechanism. Price guarantees contain the asset deflation by creating another distortion that props up the foreign investors' demand for emerging markets assets. Quantitative simulation analysis shows the strong interaction of these two distortions in driving the dynamics of asset prices, consumption and the current account. Price guarantees are found to be effective for containing Sudden Stops but at the cost of introducing potentially large distortions that could lead to 'overvaluation' of emerging markets assets.

*Work on this project began while Mendoza was a visiting scholar at the Research Department of the Inter-American Development Bank. Comments and suggestions by Guillermo Calvo, Reuven Glick, Olivier Jeanne, Urban Jermann, Alejandro Izquierdo, Katherine Smith, Linda Tesar and Diego Valderrama are gratefully acknowledged. 


\section{Introduction}

The Sudden Stop phenomenon of emerging markets crises is characterized by three stylized facts: a sudden reversal of private capital inflows and current account deficits, a collapse in production and private absorption, and large relative price corrections in domestic goods prices and asset prices. A large fraction of the literature on this subject is based on the premise that world capital markets are inherently imperfect, and hence prone to display contagion and overreaction in the determination of asset positions and asset prices relative to levels consistent with "fundamentals" (see Arellano and Mendoza (2003) for a short survey of this literature). The findings of some of this literature suggest that an international financial organization (IFO) could help prevent Sudden Stops by providing ex ante price guarantees for the emerging-markets asset class. Calvo (2002) put forward a formal proposal for setting up this facility.

The goal of ex-ante price guarantees is to create a trading environment in which emergingmarkets asset prices can be credibly expected to remain above the crash levels that trigger Sudden Stops driven by international capital market frictions. Calvo views this facility as keen to an open-markets operation facility: it would commit to exchange a liquid, riskless asset (e.g., short-term U.S. T-bills) for an index of emerging markets assets whenever the value of the index falls by a certain amount, and would re-purchase the riskless asset when the index price recovers. The optimal response of market participants would incorporate their expectations that these guarantees would be executed if a systemic fire-sale were to crash emerging-markets asset prices, and hence a properly-designed system of price guarantees could rule out rational expectations equilibria in which Sudden Stops driven by financial frictions can take place. If these frictions are the only cause of Sudden Stops and the support of the probability distribution of the events that can cause Sudden Stops is known (i.e., if there are no truly "unexpected" shocks), the facility would rarely trade.

A potentially important drawback of the above system of price guarantees is that it would strengthen moral hazard incentives among global investors. Everything else the same, the introduction of the guarantees would increase the foreign investors' demand for emerging markets assets, since the downside risk of holding these assets in bad states of nature is transferred to the IFO providing the 
guarantees. This can be a serious drawback because the moral hazard argument itself has been forcefully put forward as a competing explanation of Sudden Stops, and has been used to propose major reforms to the international financial system (see the report of the Meltzer Commission and the article by Lerrick and Meltzer (2001)).

Proponents of the moral hazard view argue that Sudden Stops are induced by excessive indebtedness of emerging economies driven by the expectation of private capital market participants that IFOs will bail out countries in financial difficulties. Based on this premise, Lerrick and Meltzer (2001) argue for the use of ex-post price guarantees to be offered by an IFO to anchor the orderly resolution of a default once it has been announced and agreed to with the IFO. The IFO would determine the crash price of the defaulted asset and would require the country to commit to re-purchase the asset at its crash price (making the commitment credible by having the IFO commit itself to buy the asset at a negligible discount below the crash price if the country were unable to buy it). If the only cause of Sudden Stops is moral hazard, the announcement of this arrangement should remove the moral hazard distortion and reduce debt levels, and in practice the arrangement itself would rarely be activated.

The tension between the financial frictions and moral hazard approaches to explain Sudden Stops and their alternative proposals for using price guarantees reflect an important tradeoff that ex ante price guarantees create. On one hand, ex ante price guarantees could endow IFOs with an effective policy tool to prevent and manage Sudden Stops driven by frictions affecting international capital markets. On the other hand, ex-ante guarantees could end up making matters worse by strengthening moral hazard incentives (even if it were true that capital market frictions were the only cause of the Sudden Stops of the last decade).

The financial frictions-moral hazard tradeoff implies that making the case for ex ante price guarantees requires their advocates to show that it is possible to design a system of price guarantees such that its benefits, in terms of undoing the distortions induced by financial frictions, outweighs its costs, in terms of inducing moral hazard. The goal of this paper is to study this issue from the perspective of the quantitative predictions of a dynamic, stochastic general equilibrium model of asset pricing and current 
account dynamics. The model is based on the setup proposed by Mendoza and Smith (2004), in which margin constraints and asset trading costs produce outcomes consistent with some of the key features of a Sudden Stop. This paper adds to their framework an IFO that offers ex ante guarantees to foreign investors on the asset prices of an emerging economy. Quantitative simulation analysis is used to study how these guarantees affect Sudden Stops and the financial frictions-moral hazard tradeoff. We are interested in particular in studying how the guarantees affect asset positions, asset price volatility, business cycle dynamics, and the magnitude and probability of Sudden Stops.

Asset price guarantees have not been widely studied in quantitative equilibrium asset pricing theory, with the notable exception of the work by Ljungqvist (2000), and they have yet to be introduced into the research program dealing with quantitative models of Sudden Stops. The theoretical literature and several policy documents on Sudden Stops have examined various aspects of the financial-frictions and moral-hazard hypotheses separately. From this perspective, one contribution of this paper is that it studies the interaction between these two hypotheses in a unified dynamic equilibrium framework from which we can derive quantitative predictions.

The Mendoza-Smith model that serves as the starting point for the model of this paper is a model in which two financial frictions play a central role in causing Sudden Stops: a margin constraint on foreign borrowing faced by the agents of an emerging economy, and trading costs incurred by foreign securities firms specialized in trading the equity of the emerging economy. Margin constraints and trading costs are intended to represent the collateral constraints and informational frictions that have been widely studied as determinants of Sudden Stops (see, for example, Calvo (1998), Izquierdo (2000), Calvo and Mendoza (2000), Caballero and Krishnamurty (2001), Mendoza (2004), Paasche (2001) and Schneider and Tornell (1999)).

This paper introduces asset price guarantees into the Mendoza-Smith model in the form of exante guarantees offered to foreign investors on the return (or equivalently, the liquidation price) of the emerging economy's assets. An IFO offers these guarantees and finances them with a lump-sum tax on foreign investors. Both the agents in the emerging economy and foreign investors are aware of the IFO's 
guarantees policy when formulating their optimal asset demands. Hence, forward-looking equity prices reflect the effects of the margin constraints and trading costs as well as the effects of the ex-ante price guarantees. The setup of the price guarantees is similar to the one proposed in Ljungqvist's (2000) closed-economy, representative-agent analysis, but framed in the context of what is effectively a twoagent equilibrium asset pricing model and extended to incorporate margin constraints and trading costs.

The price guarantees, which in the model are keen to a "put option" with minimum return, have different implications depending on the level at which they are set. There are levels of the guarantees so low that they never bind, thus making the model yield outcomes identical to those of the Mendoza-Smith model. At the other extreme, there are levels of the guarantees so high that they would always bind and would yield prices and asset allocations dominated by moral hazard incentives. The key region for the study of the financial frictions-moral hazard tradeoff of price guarantees is therefore the region in which the guarantees are "not too high and not too low." In this region, there is a non-trivial tradeoff between using the guarantees to undo the effects of the credit-market imperfections and strengthening the incentives for foreign investors to over-invest in the small open economy (or for the emerging economy to “over-borrow” from abroad).

The paper is organized as follows. Section 2 presents the model and characterizes the competitive equilibrium in the presence of margin constraints, trading costs and ex ante price guarantees. Section 3 studies key properties of this equilibrium that illustrate the nature of the financial frictionsmoral hazard tradeoff of price guarantees. Section 4 represents the competitive equilibrium as a recursive, rational expectations equilibrium and proposes a solution algorithm. Section 5 conducts the quantitative analysis and Section 6 concludes.

\section{The Analytical Framework}

Consider a small open economy (i.e., the emerging economy) inhabited by a representative household that rents out labor and a time-invariant stock of capital to a representative firm. Households can trade the equity of this firm with a representative foreign securities firm specialized in trading the emerging economy's equity, and can also access a global credit market of one-period bonds. In addition, 
an IFO operates a facility that provides price guarantees to foreign traders on their holdings of the emerging economy's equity. When foreign traders wish to liquidate the emerging economy's equity they can do so at either the current market price or the IFO's guaranteed price, whichever is higher. Dividend payments on the emerging economy's equity are stochastic and vary in response to exogenous productivity shocks. Since the probability distribution of equilibrium dividend payments is public knowledge, the IFO can setup price guarantees so as to effectively guarantee a minimum rate of return to foreign traders investing in the emerging economy. Markets of contingent claims are incomplete (because trading equity and bonds does not allow domestic households to fully hedge income uncertainty), and the credit market is imperfect (because of margin constraints and trading costs).

\subsection{The Emerging Economy}

The representative firm inside the small open economy produces a single tradable commodity by combining labor $(n)$ and a time-invariant stock of physical capital $(k)$ using a Cobb-Douglas technology: $\exp \left(\varepsilon_{t}\right) F(k, n)$, where $\varepsilon$ is a Markov productivity shock. This firm participates in competitive factor and goods markets taking the real wage $(w)$ as given. Thus, the choice of labor input consistent with profit maximization on the part of the firm yields standard marginal productivity conditions for labor demand and the rate of dividend payments $(d)$ :

$$
\begin{aligned}
& w_{t}=\exp \left(\varepsilon_{t}\right) F_{n}\left(k, n_{t}\right) \\
& d_{t}=\exp \left(\varepsilon_{t}\right) F_{k}\left(k, n_{t}\right)
\end{aligned}
$$

The small open economy is inhabited by an infinitely-lived representative household. The household chooses intertemporal sequences of consumption $(c)$, labor supply $(n)$, equity holdings $(\alpha)$, and foreign bond holdings (b) so as to maximize Epstein's (1983) stationary cardinal utility function:

$$
U(c, n)=E_{0}\left[\sum_{t=0}^{\infty} \exp \left\{-\sum_{\tau=0}^{t-1} v\left(c_{\tau}-h\left(n_{\tau}\right)\right)\right\} u\left(c_{t}-h\left(n_{t}\right)\right)\right]
$$

This utility function is a time-recursive, Von Neumann-Morgenstern intertemporal utility index with an endogenous rate of time preference (it is the stochastic representation of the classic Uzawa utility function 
with endogenous discounting). The period utility function $u($.$) is a standard, concave, twice-continuously$ differentiable utility function. The function $v($.$) is the time preference function, which is also concave and$ twice-continuously differentiable. The argument of both functions is a composite good defined by consumption minus the disutility of labor $c-h(n)$, where $h($.$) is an increasing, convex, continuously-$ differentiable function. Greenwood, Hercowitz and Huffman (1988) introduced this composite good as a way to eliminate the wealth effect on labor supply. As Mendoza and Smith (2004) showed, this property of preferences plays an important role in separating the equilibrium dynamics of wages, dividends, labor and output from those driving consumption, saving and portfolio choices.

The intertemporal utility function with endogenous time preference has the property that a change in date-t consumption has not only the standard effect on date-t marginal period utility, but also an "impatience effect," by which the change in date-t consumption alters the subjective discount rate at which all future period utility flows are discounted. Epstein showed that the size of this impatience effect is limited by the conditions required for these preferences to be consistent with consumption smoothing.

Utility functions with endogenous impatience are commonly used in models of small open economies to obtain well-defined long-run equilibria for holdings of foreign assets in which the exogenous world real interest rate equals the long-run rate of time preference (see for example Obstfeld (1981) or Mendoza (1991)). ${ }^{1}$ In models with credit constraints like the one studied here, these preferences have the additional advantage that they can be used to support long-run equilibria in which credit constraints can be binding (see Section 3 for details).

The household maximizes lifetime utility subject to the following budget constraint:

$$
c_{t}=\alpha_{t} k d_{t}+w_{t} n_{t}+q_{t}\left(\alpha_{t}-\alpha_{t+1}\right) k-b_{t+1}+b_{t} R
$$

where $\alpha_{t}$ and $\alpha_{t+1}$ are beginning- and end-of-period shares of domestic capital owned by households, $q_{t}$ is the price of equity, and $R$ is the world real interest rate (which is kept constant for simplicity).

\footnotetext{
${ }^{1}$ Arellano and Mendoza (2003) describe other alternatives used with a similar purpose in the literature, such as the Aiyagari-Hugget setup in which a constant rate of time preference is set lower than the world interest rate (so that precautionary savings pins down a well-defined ergodic distribution of wealth), or formulations of asset markets with ad-hoc world interest rate functions that depend on debt or long-run costs of adjustment in net foreign assets.
} 
International loan contracts incorporate a collateral constraint in the form of a margin clause by which the stock of foreign debt of the small open economy cannot exceed the fraction $\kappa$ of the market value of the SOE's equity holdings:

$$
b_{t+1} \geq-\kappa q_{t} \alpha_{t+1} k, \quad 0 \leq \kappa \leq 1
$$

Margin clauses of this form are widely used in international capital markets. In some instances they are imposed by regulators with the aim of limiting the exposure of financial intermediaries to idiosyncratic risk in their lending portfolios, but they are also widely used by investment banks and other lenders as a mechanism to manage default risk (they can take the form of explicit margin constraints linked to the value of specific securities offered as collateral, or implicit margin requirements linked to the volatility of returns of an asset class or subclass as those implied by value-at-risk collateralization). Margin clauses are a particularly effective collateral constraint (compared to constraints like the wellknown Kiyotaki-Moore constraint that limits debt to the discounted liquidation value of assets one period ahead) because: (a) custody of the securities that constitute the collateral is surrendered at the time the credit contract is entered and (b) margin calls to make up for shortfalls in the market value of the collateral are automatic once the value of the securities falls below the value at which they were marked.

Households in the small open economy also face a short-selling constraint in the equity market: $\alpha_{t+1} \geq \chi$ with $-\infty<\chi<1$ for all $t$. This constraint is necessary in order to make the margin constraint have a non-trivial role. Otherwise, any borrowing limit in the bond market implied by a binding margin constraint could always be undone by taking a sufficiently short equity position.

\subsection{The Foreign Securities Firm, the IFO \& the Price Guarantees}

The representative foreign securities firm obtains funds from international investors and specializes in investing them in the small open economy's equity. The securities firm maximizes its net present value discounted at the stochastic discount factors relevant for its international clients (i.e., the world interest rate). Thus, the foreign traders' problem is to choose their sequence of equity holdings $\alpha_{t+1}{ }^{*}$, for $t=1, \ldots, \infty$, so as to maximize 


$$
D=E_{0}\left[\sum_{t=0}^{\infty} R^{-t}\left(\alpha_{t}^{*} k\left(d_{t}+\max \left(q_{t}, \tilde{q}_{t}\right)\right)-q_{t} \alpha_{t+1}^{*} k-q_{t} k\left(\frac{a}{2}\right)\left(\alpha_{t+1}^{*}-\alpha_{t}^{*}+\theta\right)^{2}-k T_{t}^{*}\right)\right] .
$$

The total net return paid by the foreign securities firm to its shareholders at each date $t$ is the sum of: (a) dividends collected on its share of the small open economy's capital ( $\left.\alpha{ }_{t}{ }^{*} k d_{t}\right)$, plus (b) proceedings from the sale of equity holdings $\left(\alpha_{t}{ }^{*} k \max \left(q_{t}, \tilde{q}_{t}\right)\right)$, which are executed at either the market price $q_{t}$ or the guaranteed price $\tilde{q}_{t}$, whichever is greater, minus (c) new equity purchases $\left(q_{t} \alpha_{t+1}{ }^{*} k\right)$, minus (d) total trading costs, which include a cost that depends on the size of net trades $\left(\alpha_{t+1}{ }^{*}-\alpha_{t}{ }^{*}\right)$ and a recurrent trading cost $(\theta)$, minus (e) lump sum taxes paid to the IFO $\left(k T_{t}^{*}\right)$. Trading costs are specified in quadratic form, as is typical in the equilibrium asset pricing literature on trading costs, so $a$ is a standard adjustment-cost coefficient.

The IFO buys equity from the foreign traders at the guaranteed price and sells it at the equilibrium price. Thus, the IFO's budget constraint is:

$$
k T_{t}^{*}=\max \left(0,\left(\tilde{q}_{t}-q_{t}\right) \alpha_{t}^{*} k\right)
$$

If the price guarantee is not executed, the tax is zero. If the guarantee is executed, the IFO sets the lumpsum tax to match the value of the executed price guarantee (i.e., the extra income that foreign traders earn by selling equity to the IFO instead of selling it in the equity market).

Since the return on equity is $R_{t}^{q} \equiv\left[d_{t}+q_{t}\right] / q_{t-1}$, the IFO's offer to guarantee the date-t price implies a guaranteed minimum return on the emerging economy's equity. The implied guaranteed rate of return is $\tilde{R}_{t}^{q}=\left[\tilde{q}_{t}+d_{t}\right] / q_{t-1}$. Alternatively, the IFO could fix a guaranteed return and foreign traders could then determine the schedule of price guarantees implicit in the guaranteed return.

\subsection{Equilibrium}

A competitive equilibrium for this model economy is given by stochastic intertemporal sequences of allocations $\left[c_{t}, n_{t}, b_{t+1}, \alpha_{t+1}, \alpha_{t+1}^{*}, T_{t}^{*}\right]_{t=0}^{\infty}$ and prices $\left[w_{t}, d_{t}, q_{t}\right]_{t=0}^{\infty}$ such that: (a) households maximize the utility function (3) subject to the constraints (4) and (5) and the short-selling constraint, taking prices, wages and dividends as given, (b) domestic firms maximize profits by satisfying equations (1) and (2), 
taking wages and dividends as given, (c) the foreign securities firm maximizes (6) taking the price of equity, the price guarantees and lump-sum taxes as given, (d) the budget constraint of the IFO in equation (7), holds and (e) the equity market clears (i.e., $\alpha_{t}+\alpha_{t}{ }^{*}=1$ for all $t$ ). Section 4 exploits the recursive representation of this rational expectations equilibrium to design a numerical solution algorithm.

\section{Characterizing the Financial Frictions-Moral Hazard Tradeoff}

The tradeoff between the distortions introduced by margin constraints and trading costs and those introduced by price guarantees can be illustrated by studying the conditions that determine the optimal decisions of domestic households and foreign traders. Consider first the domestic households. The firstorder conditions of their maximization problem are:

$$
\begin{gathered}
U_{C_{t}}(c, n)=\lambda_{t} \\
h^{\prime}\left(n_{t}\right)=w_{t} \\
q_{t}\left(\lambda_{t}-\eta_{t} \kappa\right)=E_{t}\left[\lambda_{t+1}\left(d_{t+1}+q_{t+1}\right)\right]+v_{t} \\
\lambda_{t}-\eta_{t}=E_{t}\left[\lambda_{t+1} R\right]
\end{gathered}
$$

In these expressions, $U_{c_{t}}(c, n)$ is the derivative of the stationary cardinal utility function with respect to $c_{t}$

(which includes the impatience effect), and $\lambda_{t}, \eta_{t}$ and $v_{t}$ are the Lagrange multipliers on the budget constraint, the margin constraint, and the short-selling constraint respectively.

Condition (8) has the standard interpretation: at equilibrium, the marginal utility of wealth equals the lifetime marginal utility of consumption. Condition (9) equates the marginal disutility of labor with the real wage. This is the case because the Greenwood-Hercowitz-Huffman composite good implies that the marginal rate of substitution between $c_{t}$ and $n_{t}$ is equal to the marginal disutility of labor $h^{\prime}\left(n_{t}\right)$, and

thus is independent of $c_{t}$. It follows from this result that condition (9) together with (1) and (2) determine the equilibrium values of $n_{t}, w_{t}$ and $d_{t}$ as well as the equilibrium level of output. These "supply-side" solutions are independent of the dynamics of consumption, saving, portfolio choices and equity prices, and are therefore also independent of the distortions induced by financial frictions and price guarantees. 
The neutrality of the financial frictions with regard to the "supply side" of the domestic economy follows from admittedly strong assumptions but it simplifies significantly the solution of the model by separating the equilibrium path of dividends from the savings and portfolio decisions. Mendoza (2004) studies the business cycle implications of margin constraints in a small-open-economy model with endogenous investment in which financial frictions affect dividends, investment and the Tobin Q, but abstracting from international equity trading.

Conditions (10) and (11) are Euler equations for the accumulation of equity and bonds respectively. Following Mendoza and Smith (2004), these conditions can be combined to derive expressions for the forward solution of equity prices and the excess return on equity from the perspective of the emerging economy. The forward solution for equity prices is:

$$
q_{t}=E_{t}\left(\sum_{i=0}^{\infty}\left[\prod_{j=0}^{i}\left(1-\frac{\eta_{t+j}}{\lambda_{t+j}} \kappa\right)^{-1}\right] M_{t+1+i} d_{t+1+i}\right)
$$

where $M_{t+1+i} \equiv \lambda_{t+1+i} / \lambda_{t}$, for $i=0, \ldots, \infty$, is the intertemporal marginal rate of substitution between $c_{t+1+i}$ and $c_{t}$. The excess return on domestic equity is:

$$
E_{t}\left[R_{t+1}^{q}\right]-R=\frac{\eta_{t}(1-\kappa)-\frac{v_{t}}{q_{t}}-\operatorname{COV}_{t}\left(\lambda_{t+1}, R_{t+1}^{q}\right)}{E_{t}\left[\lambda_{t+1}\right]}
$$

Given these results, the forward solution for equity prices can also be expressed as:

$$
q_{t}=E_{t}\left(\sum_{i=0}^{\infty}\left[\prod_{j=0}^{i}\left(E_{t}\left[R_{t+1+j}^{q}\right]\right)^{-1}\right] d_{t+1+i}\right)
$$

Expressions (12)-(14) show the direct and indirect effects that margin calls have on the demand for equity of the small open economy, and thus on its valuation of equity and excess returns. The direct effect of a date- $t$ margin call is represented by the term $\eta_{t}(1-\kappa)$ in (13), or the term $\eta_{t} \kappa$ in (12): When a margin call occurs, domestic agents "fire sale" equity in order to meet the call and satisfy the borrowing constraint. Everything else the same, this effect lowers the date- $t$ equity price and increases the expected excess return for $t+1$. The indirect effect of the margin call is reflected in the fact that a binding 
borrowing limit makes "more negative" the co-variance between the marginal utility of consumption and the rate of return on equity (since a binding borrowing limit hampers the households' ability to smooth consumption). The direct and indirect effects increase the rate at which future dividends are discounted in the domestic agents' valuation of asset prices, and thus reduce their demand for equity. Interestingly, the date- $t$ equity price along the domestic agents' demand curve is reduced by a margin constraint that is binding at date $t$ or by any expected binding margin constraint in the future. As a result, equity prices and the domestic demand for equity can be distorted by the margin requirements even in periods in which the constraint does not bind.

If domestic agents facing margin calls could trade assets in a frictionless, perfectly-competitive market in which the world demand for the emerging economy's assets is infinitely-elastic at the level of the fundamentals price, the margin call would trigger a portfolio reallocation effect without any price movement. However, if the world demand for the emerging economy's assets is less than infinitelyelastic, the equilibrium asset price would fall. Since households were already facing a binding margin constraint at the initial price, the price decline would tighten further the margin constraint triggering a new round of margin calls. This downward spiral in equity prices is a variant of Fisher's debt-deflation mechanism. The Fisherian deflation magnifies the direct and indirect effects of the margin constraint.

The world demand for assets of the emerging economy is less than infinitely-elastic because of the trading costs that foreign traders incur. Define the conditional expected value of the stream of dividends discounted at the world interest rate as the "fundamentals" price $q_{t}^{f} \equiv E_{t}\left(\sum_{i=0}^{\infty} R^{-(t+1+i)} d_{t+1+i}\right)$. The first-order condition for the optimization problem of the foreign traders implies then the following asset demand function:

$$
\left(\alpha_{t+1}^{*}-\alpha_{t}^{*}\right)=\frac{1}{a}\left(\frac{q_{t}^{f}}{q_{t}}-1+\frac{E_{t}\left[\sum_{i=1}^{\infty} R^{-(t+i)}\left(\max \left(q_{t+i}, \tilde{q}_{t+i}\right)-q_{t+i}\right)\right]}{q_{t}}\right)-\theta
$$


This expression states that the foreign traders' demand for the emerging economy's assets is an increasing function of: (a) the percent deviation of $q_{t}^{f}$ relative to $q_{t}$ (with an elasticity equal to $1 / a$ ) and (b) the expected present discounted value of the "excess prices" induced by the price guarantees in units of today's equity price. ${ }^{2}$ The first effect reflects the influence of the per-trade trading costs. If trading were costless and recurrent costs were zero, the foreign traders' demand function would be infinitely-elastic at the fundamentals price and, as explained earlier, margin calls could not affect asset prices. The second effect represents the "moral hazard effect" of the price guarantees, which acts as a "demand shifter" in the foreign traders' demand function. Foreign traders that expect price guarantees to be executed at any time in the future have a higher demand for the emerging economy's assets at date $t$ than they would in a market without price guarantees. The recurrent trading costs are also a demand shifter (the foreign trader's demand function is lower the higher is $\theta$ ).

Putting together the previous results, the tradeoff between the distortions created by the financial frictions and those induced by the moral hazard effect can be summarized as follows. Suppose the date- $t$ asset price in a market without margin constraints and without price guarantees is determined at the intersection of the domestic agents' and foreign traders' demand curves ( $H H$ and $F F$ respectively) at point A in Figure 1.

Figure 1. Equilibrium in the Date-t Asset Market

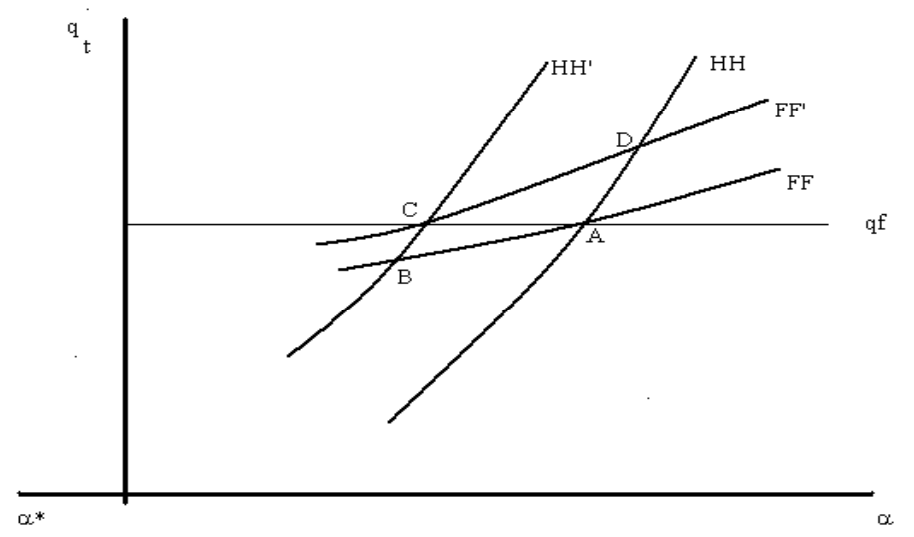

\footnotetext{
${ }^{2}$ The present value of excess prices has an equivalent representation in terms of the present value of guaranteed returns $E_{t}\left[\sum_{i=1}^{\infty} R^{-(t+i)} s_{t+i}\left(q_{t+i}\left[\tilde{R}_{t+i}-R_{t+i}^{q}\right]\right)\right]$, with $s_{t+i}=1$ if the guarantee is executed and $s_{t+i}=0$ otherwise.
} 
The demand function of foreign traders is simply the reduced form solved for in (15), shown as an upward-slopping curve because the horizontal axis measures $\alpha$, which is the complement of $\alpha^{*}$. There is no closed-form solution for $H H$, so the depicted curve is intended only to facilitate intuition. We follow Aiyagari and Gertler (1999) in plotting $H H$ as an upward-slopping curve because domestic agents respond to wealth, intertemporal-substitution and portfolio-composition effects in choosing their equity holdings. Depending on which effect dominates, $H H$ can be downward or upward slopping.

Suppose that a margin call hits domestic agents because an adverse shock hits the economy when their level of debt is "sufficiently high" relative to the value of their asset holdings. As a result, the $H H$ curve shifts to $H H^{\prime}$ '. In Figure 1, $H H^{\prime}$ ' represents the "final" demand function, including the magnification effects of the Fisherian debt-deflation mechanism. Without price guarantees, the date- $t$ equilibrium price would fall to point B. This is the "Sudden Stop scenario," in which margin calls result in a decline in asset prices and adjustments in the current account and consumption.

Enter now an IFO that sets a price guarantee higher than the market price at B. Since the guarantee is triggered, the foreign traders' demand curve shifts to $F F^{\prime}$ and the new date- $t$ price is determined at point $\mathrm{C}$, which yields the fundamentals price. The scenario depicted here is an ideal one in which the IFO is assumed to know exactly at what level to set the guaranteed price so as to stabilize the market price at the fundamentals level. If the guarantee is "too low" (i.e., below the price at B) it would have no effect on the equilibrium price implied by the financial frictions, and thus price guarantees would be irrelevant. If the guarantee is "too high" it could lead to a price higher than the fundamentals price with the "overpricing" even larger than the "underpricing" that occurs at C. ${ }^{3}$ Hence, ex-ante price guarantees do not necessarily reduce the volatility of asset prices (as the numerical analysis of Ljungqvist (2000) also showed).

Interestingly, Figure 1 illustrates an outcome in which, even tough the moral hazard effect props up the foreign traders' asset demand for any given price, at equilibrium domestic agents are the ones that

\footnotetext{
${ }^{3}$ This is under the assumption that the guarantees are used to stabilize asset prices. If the aim is to stabilize asset holdings (i.e., portfolio flows) then the IFO would want to set price guarantees to yield prices higher than at C.
} 
end up owning more domestic assets relative to the equilibrium without price guarantees. Domestic agents hold more equity at $\mathrm{C}$ (with binding margin constraints and price guarantees) than at $\mathrm{B}$ (with binding margin constraints and no guarantees), or at $\mathrm{D}$ (with price guarantees and non-binding margin constraints) than at A (without price guarantees and non-binding margin constraints). This is the case because the demand function of domestic agents is upward-slopping and steeper than the foreign traders' demand curve, so when foreign traders increase their demand for equity bidding up the price, domestic agents have a lower demand elasticity and thus end up buying more equity. In this case, and if the margin constraint binds, this higher level of domestic equity holdings also means that the domestic economy's foreign debt would be higher than in the absence of the guarantees. Thus, the model can predict that price guarantees offered to foreign traders lead to excessive holdings of equity and excessive borrowing by domestic agents.

From the perspective of the full dynamic stochastic general equilibrium model, Figure 1 is just a partial equilibrium snapshot of the date- $t$ asset market. The forward-looking behavior of domestic households and foreign traders implies that changes that affect the date- $t$ asset market spillover into the market outcomes at other dates and vice versa. For example, the price guarantee may not be in force at $t$ but the expectation of executing future price guarantees will shift upward the $F F$ curve at $t$. Similarly, the margin constraint may not bind at $t$, but the expectation of future margin calls is enough to shift the date- $t$ $H H$ curve. Hence, determining the effects of the price guarantees on the dynamics of consumption, the current account, bond holdings, equity holdings and equity prices is a difficult task. Given the lack of closed-form solutions for the model's equilibrium allocations and prices, the only way to deal with these issues is by exploring the quantitative implications of the model via numerical simulation.

\section{Recursive Equilibrium and Solution Method}

In the recursive representation of the equilibrium, the state variables are the current holdings of assets and bonds in the emerging economy, $\alpha$ and $b$, and the realizations of productivity shocks listed in the vector $\varepsilon$. The state space of asset positions spans the discrete grid of NA nodes $A=\left\{\alpha_{1}<\alpha 2<\ldots<\alpha_{N A}\right\}$ 
with $\alpha_{1}=\chi$, and the state space of bonds spans the discrete grid of NB nodes $B=\left\{b_{1}<b_{2}<\ldots<b_{N B}\right\}$. The endogenous state space is thus defined by the discrete set $Z=\mathrm{A} \times \mathrm{B}$ of $\mathrm{NA} \times \mathrm{NB}$ elements. Productivity shocks follow an asymptotically-stationary, two-point Markov chain with realizations $\mathrm{E}=\left\{\varepsilon_{\mathrm{L}}<\varepsilon_{\mathrm{H}}\right\}$.

Equilibrium wages, dividends, labor and output are determined by solving the supply-side system given by equations (1), (2), (9) and the production function. The solutions can be represented as functions of the state space that depend only on $\varepsilon: w(\varepsilon), d(\varepsilon), n(\varepsilon)$ and $F(\varepsilon)$.

Assume a continuous, nonnegative asset pricing function that is taken as given by foreign traders and agents in the emerging economy. This conjectured pricing function maps the state space into equity prices $\hat{q}(\alpha, b, \varepsilon): E \times Z \rightarrow R^{+}$. Take as given also conjectured decision rules for assets and bonds: $\hat{\alpha}^{\prime}(\alpha, b, \varepsilon), \hat{b}^{\prime}(\alpha, b, \varepsilon): E \times Z \rightarrow R^{+}$. For any initial state $(\alpha, b, \varepsilon)$, the conjectured pricing function must satisfy $\hat{q}(\alpha, b, \varepsilon) \in\left[q^{\min }(\alpha, b, \varepsilon), q^{\max }(\alpha, b, \varepsilon)\right]$, where:

$$
\begin{gathered}
q^{\min }(\alpha, b, \varepsilon)=\left[q^{f}(\varepsilon)+G(\alpha, b, \varepsilon)\right] /[1+a(\alpha-\chi+I(\alpha, b, \varepsilon) \theta)] \\
q^{\max }(\alpha, b, \varepsilon)=\left[q^{f}(\varepsilon)+G(\alpha, b, \varepsilon)\right] /\left[1+a\left(\alpha-\alpha_{N A}+I(\alpha, b, \varepsilon) \theta\right)\right]
\end{gathered}
$$

and $G(\alpha, b, \varepsilon)$ represents the expected present discounted value of the "excess prices" induced by the price guarantees (which can be computed recursively using $\hat{\alpha}^{\prime}(\alpha, b, \varepsilon), \hat{b}^{\prime}(\alpha, b, \varepsilon), \hat{q}(\alpha, b, \varepsilon)$ and the Markov process of productivity shocks). The prices in (16) and (7) are the maximum and minimum asset prices along the foreign traders' demand curve. These bounds of the pricing function follow from the fact that when domestic agents hit either the short-selling constraint or the upper bound $\alpha_{N A}$, the foreign traders are at the "short side" of the market.

Given the above conjectured decision rules and pricing function, the recursive equilibrium can be characterized in two ways. One approach is an extension of the setup of iterations on the asset pricing function "outside" the optimization problem of the small open economy proposed by Mendoza and Smith (2004). This approach uses the foreign trader's demand function and the market-clearing condition in the asset market to construct a conjectured law of motion of equity holdings, and solves a dynamic 
programming problem only on bond holdings for the small open economy given the conjectured law of motion and pricing function for equity. This dynamic programming problem yields optimal consumption plans for domestic agents and these plans are used to compute an "actual" pricing function that can be compared with the conjectured pricing function. The conjecture is then updated with a Gauss-Siedel rule and the process repeated until the conjectured and actual pricing functions satisfy a convergence criterion.

Iterations on the pricing function "outside" the optimization problem of the small open economy have the disadvantage that they take several hours to compute and may not converge to small errors. This is because the algorithm is solving for a fixed point by seeking stable convergence to equilibrium prices that clear the equity market starting from an arbitrary initial pricing function. Hence, the second approach to represent the equilibrium of the model in recursive form appeals to a "quasi-planning problem" that yields a more efficient solution method in which asset prices are computed without error and the contraction-mapping properties of the Bellman equation are exploited to speed convergence.

The quasi-planning-problem approach starts with a conjecture for the function representing the expected present value of "excess prices" induced by price guarantees, $G(\alpha, b, \varepsilon)$. Given this, the optimal plans of domestic agents are represented as the solution to the following dynamic programming problem:

$$
V(\alpha, b, \varepsilon)=\max _{\alpha^{\prime}, b^{\prime}}\left\{u(c-h(n(\varepsilon)))+\exp (-v(c-h(n(\varepsilon)))) E\left[V\left(\alpha^{\prime}, b^{\prime}, \varepsilon^{\prime}\right)\right]\right\}
$$

subject to:

$$
\begin{gathered}
c=\alpha k d(\varepsilon)+w(\varepsilon) n(\varepsilon)+\frac{q^{f}(\varepsilon)+G(\alpha, b, \varepsilon)}{1+a \theta+a\left(\alpha-\alpha^{\prime}\right)} k\left(\alpha-\alpha^{\prime}\right)-b^{\prime}+b R \\
b^{\prime} \geq-\kappa \frac{q^{f}(\varepsilon)+G(\alpha, b, \varepsilon)}{1+a \theta+a\left(\alpha-\alpha^{\prime}\right)} \alpha^{\prime} k
\end{gathered}
$$

In this formulation, domestic agents choose both equity and bond positions. Equity prices have been displaced with the prices along the demand curve of foreign traders by imposing market clearing in the equity market and solving for the equity prices implied by equation (15).

Once the above dynamic programming problem is solved, the resulting optimal plans for equity holdings are plugged into equation (15) to derive the "actual" asset pricing function for the given initial 
conjecture of $G($.$) . The decision rules for bonds and equity and this "actual" asset pricing function are$ then used to solve for the "actual" $G(\alpha, b, \varepsilon)$ function (i.e., the function that returns the expected present discounted value of the excess of guaranteed over market prices conditional on any initial triple $(\alpha, b, \varepsilon)$ ). The conjectured and actual $G$ functions are then combined to create a new conjecture of $G(\alpha, b, \varepsilon)$ using a Gauss-Siedel rule and the procedure starts again with the Bellman equation (18). The process is repeated until the actual and conjectured $G$ functions converge, so that the conjectured excess prices function $G(\alpha, b, \varepsilon)$ that is taken as given in the dynamic programming problem is consistent with the actual excess prices function implied by the asset price and policy functions that are endogenous outcomes of that problem.

The drawback of this quasi-planning-problem method is that in principle it represents the equilibrium of a market in which the emerging economy is keen to a Stackelberg leader that internalizes the demand function of foreign traders. Analysis of the Benveniste-Sheinkman equations of the dynamic programming problem shows that, comparing the Euler equations for bonds and equity of the competitive equilibrium with those of the quasi planning problem, this feature does not distort the Euler equation for bonds but it does distort the one for equity. The distortion can be expressed as a multiple of the return on equity that has an ambiguous sign and depends on how much the equity price along the foreign traders' demand curve varies with $\alpha$ and $\alpha^{\prime}$. We face therefore a tradeoff between a method that solves the competitive equilibrium with error in the pricing function and a method that computes prices without error but does so by deviating from the competitive equilibrium. For small values of $a$ (i.e., when the price elasticity of the foreign traders' demand function is high), the quasi planning problem yields negligible distortions. ${ }^{4}$ Since this method is also considerably faster, we chose to use the quasi-planning problem method.

The optimal decision rules obtained after the solution method converges constitute a recursive, rational expectations equilibrium for the model. At this recursive equilibrium, the decision rules

\footnotetext{
${ }^{4}$ In the four sets of simulations reviewed in Section 5 the maximum absolute value of the distortion ranges between 0.08 and 0.2 percent of the return on equity.
} 
determining asset holdings, bond holdings, consumption, labor, wages, dividends, the foreign traders'

asset holdings and the asset prices are such that: (a) given wages and dividends, the policy functions for $c$, $b^{\prime}, \alpha^{\prime}$ and $n$ maximize household utility and firm profits in the small open economy subject to the relevant constraints, (b) given asset prices and dividends, the choice for $\alpha^{\prime *}$ solves the maximization problem of foreign traders, (c) the IFO's budget constraint holds and (e) the market-clearing conditions for assets, goods and labor markets hold..$^{5}$

\section{Quantitative Analysis}

The functional forms that represent preferences and technology are standard isoelastic functions:

$$
\begin{gathered}
F\left(k, n_{t}\right)=k^{1-\gamma} n_{t}^{\gamma}, \quad 0 \leq \gamma \leq 1 \\
u\left(c_{t}-h\left(n_{t}\right)\right)=\frac{\left[c_{t}-h\left(n_{t}\right)\right]^{1-\sigma}-1}{1-\sigma}, \quad \sigma>1 \\
v\left(c_{t}-h\left(n_{t}\right)\right)=\beta\left[\operatorname{Ln}\left(1+c_{t}-h\left(n_{t}\right)\right)\right], \quad 0<\beta \leq \sigma \\
h\left(n_{t}\right)=\frac{n_{t}^{\delta}}{\delta}, \quad \delta>1
\end{gathered}
$$

$\gamma$ is the labor income share, $\sigma$ is the coefficient of relative risk aversion, $\beta$ is the elasticity of the rate of time preference with respect to $l+c_{t}-h\left(n_{t}\right)$, and $\delta$ determines the wage elasticity of labor supply (which is equal to $1 /(\delta-1))$. The condition $0<\beta \leq \sigma$ comes from Epstein (1983).

\subsection{Deterministic Steady State and Calibration to Mexican Data}

The calibration strategy differs from the one followed by Mendoza and Smith (2004). Their calibration normalizes the capital stock to $k=1$ and lets the steady-state equity price adjust to the value implied by the asset pricing condition given a set of parameter values that were directly inferred from the

\footnotetext{
${ }^{5}$ These properties are easy to prove noting that: (i) the Benveniste-Sheinkman equations of the Bellman equation in (18) yield the Euler equation for bond holdings of the competitive equilibrium and ensure that the Euler equation for asset holdings is satisfied up to the error implied by the distortion that depends on the price elasticity of the foreign trader's demand curve, (ii) the wage, dividend and labor functions reflect optimal decisions by households and domestic firms, (iii) the optimality condition for the maximization problem of foreign traders holds (i.e., prices and allocations satisfy the foreign trader's demand curve), and (iv) the constraints (19) and (20) combined with results (i)-(iii) ensure that the market-clearing conditions, the households' budget constraint, and the margin constraint hold.
} 
data or set to enable the model to match ratios of national accounts statistics. Here, we normalize instead the steady-state equity price so that the capital stock matches the deterministic, steady-state capital stock of a typical RBC small open economy model calibrated to Mexican data (see Mendoza (2004)). The details of this calibration procedure are provided below.

The risk aversion parameter does not appear in the model's deterministic steady-state conditions. This parameter is set at $\sigma=2$ in line with values often used in RBC studies of small open economies.

The parameter values that enter into the supply-side system are determined as follows. The labor share is set at $\gamma=0.65$, which is in line with international evidence on labor income shares. The Mexican average share of labor income in value added in an annual sample for 1988-2001 is 0.34 , but values around 0.65 are the norm in several countries and there is concern that the Mexican data may measure inaccurately proprietors income and other forms of labor income (for further details on this controversy see Mendoza (2004)). The real interest rate is set at 6.5 percent, which is the value widely used in the $\mathrm{RBC}$ literature. Since the model is set to a quarterly frequency, this implies that the gross real interest rate is $R=1.065^{1 / 4}$. The labor disutility coefficient is set to the same value as in Mendoza and Smith (2004), $\delta=2$, which implies a unitary wage elasticity of labor supply.

As in a typical RBC calibration exercise, the calibration is designed to yield a set of parameter values such that the model's deterministic steady state matches the time-series averages of the GDP shares of consumption $(s c)$, investment $(s i)$, government purchases $(s g)$ and net exports $(s n x)$ from the data. In the Mexican data, these shares are $s c=0.684, s i=0.19, s g=0.092$, and $s n x=0.034$. Since the model does not have endogenous investment or government purchases, their combined share $(0.282)$ is treated as exogenous absorption of output equivalent to 28.2 percent of steady-state GDP. In the stochastic simulations we keep the corresponding level of these exogenous expenditures constant at 28.2 percent of the value obtained for the calibrated level of steady-state output.

The typical RBC model of the small open economy features a standard steady-state optimality condition that equates the marginal product of capital net of depreciation to the world interest rate, and a 
standard law of motion for the capital stock that relates the steady-state investment rate to the steady-state capital-output ratio. Given the values of $s i, \gamma, \delta$ and $R$, these two steady-state conditions can be combined to yield implied values of the depreciation rate (dep) and the capital-output ratio $(s k)$. On an annual basis, the resulting depreciation rate is 7.75 percent and $s k$ is about 2.5 (or 10.08 on a quarterly basis).

In a deterministic steady state of the model of Section 2 in which the credit constraint does not bind and there are no price guarantees, the steady-state equity price is $q=q^{f}=d /(R-1)$. Given the calibration criterion that the steady-state marginal product of capital net of depreciation equals the net world interest rate, $q^{f}$ can be re-written as $F_{k}(k, n) /\left(F_{k}(k, n)\right.$-dep). With the Cobb-Douglas form of the production function this reduces to $q^{f}=(1-\gamma) /(1-\gamma-s i)$. Thus, if the model is to be consistent with a dividend rate that matches the long-run predictions of a typical RBC small open economy model, the steady-state equity price must be determined by the values of the labor income share and the investment rate. With the parameter values set above we obtain $q^{f}=2.19$.

Given the values of $\gamma, \delta, R$, and $q^{f}$ the steady state solutions for $n, w, k$, and $F(k, n)$ follow from solving the supply-side system conformed by (1), (2), (9) and (21). In particular, the level of the capital stock consistent with these supply-side conditions and the calibrated parameter values is $k=79$. By construction, this capital stock is also consistent with the estimated capital-output ratio of 2.5 and the observed Mexican investment rate of 0.19 .

The parameters that remain to be calibrated are the time-preference elasticity coefficient $\beta$ and the financial frictions parameters $a, \theta$ and $\kappa$. The time-preference elasticity coefficient is derived from the consumption Euler equation as follows. In a deterministic stationary state in which the margin constraint does not bind, the endogenous rate of time preference equals the real interest rate:

$$
\left(1+(s c) F(k, n)-\frac{n^{\delta}}{\delta}\right)^{\beta}=R
$$


Given the values of $R, \delta, n, F(k, n)$ and $s c$, this condition can be solved for the required value of $\beta$. The solution yields $\beta=0.0118$. The total stock of domestic savings at steady state follows then from the resource constraint as $s=[c-F(k, n)(s i+s g)-w n] /(R-1)$.

Mendoza and Smith (2004) showed that the above deterministic steady state with a non-binding margin constraint has the unappealing feature that, while there is a well-defined, unique steady-state equilibrium for savings, the allocation of the savings portfolio across bonds and equity is undetermined. The steady-state equity price equals its fundamentals level $q=q^{f}=d /(R-1)$, as shown earlier, and therefore the return on equity equals the world interest rate. But at this price and return, any portfolio of equity and bonds is consistent with the steady state as long as it satisfies the accounting identity for steady-state savings, $\alpha q^{f} k+b=s$, and the resulting $(\alpha, b)$ pair is such that $b>-\kappa \alpha q^{f} k$ and $\alpha \geq \chi$. Moreover, within this range of portfolios and given the value of $q^{f}$ implied by the calibration, it is difficult to support portfolios in which the emerging economy is actually borrowing in the bond market (i.e., portfolios with $b<0$ ). Portfolios with debt require $\alpha>0.9$. If domestic agents own less than 90 percent of the capital stock, their bond position is always positive and grows larger the smaller is $\alpha$.

The above result showing that there is a small range of debt positions in a deterministic steady state with non-binding credit constraints, and that these debt positions require a high degree of "home bias" in equity holdings, also implies that it will take relatively strong margin coefficients (i.e., low values of $\kappa$ ) to make the margin constraint bind. In particular, ruling out short positions by foreign traders, so that the largest share of domestic equity holdings is 100 percent, it takes $\kappa \leq 0.10$ for the margin constraint to bind for at least some of the feasible steady-state pairs of $(\alpha, b)$. These low values of $\kappa$ can be justified by considering that the margin constraint is intended to represent the fraction of domestic capital that is useful collateral for international debt contracts. Several studies in the literature on Sudden Stops provide different arguments suggesting that this fraction may be far less than 1 . The models proposed by Caballero and Krishnamurty (2001), Paasche (2001), Mendoza (2002), Scheneider and Tornell (2000) and others show how frictions like limited enforcement, default risk, "liability 
dollarization," and low international liquidity of shares of domestic capital of different sectors are frictions that can hamper the ability of domestic borrowers to leverage foreign debt on domestic assets.

The stochastic economy with non-binding margin constraints has the additional unappealing feature that it can lead to a degenerate long-run distribution of equity and bonds in which domestic agents hold the smallest possible fraction of equity $(\chi)$ and use only bonds to engage in consumption smoothing and precautionary savings. The reason is that, without credit constraints and zero recurrent asset-trading costs, risk-averse domestic agents demand a risk premium to hold equity (for standard equity-premium reasons) while the risk-neutral foreign traders do not. Hence, domestic agents end up selling all the equity they can to foreign traders. This process takes time because the per-trade trading costs slow the speed at which foreign traders adjust their equity holdings.

To circumvent the above problems of indeterminacy of the portfolio composition in the deterministic steady state and full downloading of domestic equity holdings in the stochastic steady state of the economy with frictionless financial markets, the calibration sets the values of the financial frictions parameters $(a, \theta$ and $\kappa)$ so that the allocations and prices obtained for the deterministic steady with nonbinding margin constraints can also be supported as the deterministic steady state of an economy with negligible (but positive) recurrent trading costs and a margin constraint that is just slightly binding. This calibration scenario is labeled the "nearly frictionless economy" (NFE).

The deterministic steady state of the NFE has well-defined, unique solutions for bond and equity allocations. In particular, foreign traders hold a stationary equity position at the price $q=q^{f} /(1+a \theta)$. Since this price is less than $q^{f}$, which is the price at which the return on domestic equity equals $R$, it follows that at this lower price $R^{q}>R$ at steady state. The ratio of the Lagrange multipliers of the margin constraint and the budget constraint can then be found to be: $\mu / \lambda=\left(R^{q}-R\right) /\left(R^{q}-R \kappa\right)$.

With the domestic agent's debt given by $b=-\kappa \alpha q k$, a unique stationary equity position can then be obtained from the steady-state consumption Euler equation when the credit constraint binds. This is the value of $\alpha$ that solves the following expression: 


$$
\left(1+\alpha k d+w n-\kappa q \alpha k(R-1)-\frac{n^{\delta}}{\delta}\right)^{\beta}=\frac{R}{1-(\mu / \lambda)}
$$

This expression illustrates the key role that the endogenous rate of time preference plays in supporting stationary equilibria with binding credit limits: it allows the rate of time preference to adjust so as to make the higher long-run level of consumption, implied by the fact that domestic agents are not allowed to build as much debt as they desire in the transition to the steady state, to be consistent with the higher effective long-run real interest rate, implied by the credit constraint. The recurrent trading cost is also critical. With $\theta=0$, the equity price equals the fundamentals price and the return on equity equals the real interest rate, and the latter would imply that $\mu \lambda=0$, so the borrowing constraint could not bind.

In this NFE scenario, the values of $\kappa, a$ and $\theta$ are set to yield a deterministic stationary state with a binding borrowing constraint in which the following conditions hold: (1) the debt-GDP ratio is in line with the empirical evidence for Mexico, (2) the allocations, factor payment rates and the equity price are nearly identical to those in the model without binding credit limit, and (3) the elasticity of the foreign trader's demand curve is relatively high. The values of the parameters are: $\kappa=0.03, \theta=0.001$ and $a=$ 0.2. These parameter values, and the values set earlier for $\gamma, \delta, \beta$, and $R$, yield values of $c, s, n, w, d, q$, and $R^{q}$ nearly identical to those obtained without a binding debt constraint, and the unique steady-state portfolio allocations are $\alpha=0.931$ and $b=-4.825$. The debt-GDP ratio is about 62 percent.

\subsection{Stochastic Simulation Framework}

The stochastic simulations are solved over a discrete state space with 78 evenly-spaced nodes in the equity grid and 120 evenly-spaced nodes in the bonds grid. The lower bound for domestic equity is set at 84 percent of the capital stock $(\chi=0.84)$, so the equity grid spans the interval $[0.84,1]$. These bounds for equity holdings, together with the "plausible" maximum equity price defined by equation (17) and the margin constraint, set the lower bound of the bond grid as $-\kappa q^{\max } k=-5.2$. This is the largest "feasible" debt that the domestic economy could leverage by holding the largest possible equity position at the highest possible price for the given grid of equity holdings. The upper bound of bonds is found by 
solving the model repeatedly starting with an upper bound on bonds that supports the steady state stock of savings with the equity position at its lowest, and then increasing the upper bound until the grid captures the support of the ergodic distribution of bonds. The resulting grid spans the interval $[-5.2,25.7]$. The segment of debt positions inside this interval is relatively small, reflecting the fact that, despite the frictions induced by asset trading costs, domestic agents still have a preference for bonds as a vehicle to smooth consumption and build a buffer stock of savings.

A lower bound on domestic equity holdings of 84 percent seems much higher than the conventional short-selling limit set at 0 but is consistent with the national aggregates targeted in the calibration. In Mexico, the average ratio of stock market capitalization to output in the period 1988-2000 was 27.6 percent. Since the calibration yields an estimate of the capital-output ratio of about 2.5 , the total value of the shares of all Mexican publicly-traded firms constitutes just 11 percent of Mexico's capital stock. A large fraction of Mexico's capital stock is owned by non-publicly-traded private and government firms and by owners of residential property, and thus does not have a liquid market in which shares are traded with foreign residents. In general, at the aggregate level of most emerging economies it is hard to argue that a large fraction of the physical capital stock has a liquid international market. Moreover, the result from the calibration exercise showing that bond positions become positive and unrealistically large when the domestic economy owns less than 90 percent of its capital also argues for a high value of $\chi$.

Stochastic productivity shocks are modeled as a two-point, symmetric Markov process that follows the "simple persistence" rule. The two points of the Markov chain and the elements of the Markov transition probability matrix are set so that they yield moments of the limiting distribution of output that match the standard deviation and first-order autocorrelation of the quarterly cyclical component of Mexico's GDP reported in Mendoza (2004) -- 2.64 percent and 0.683 respectively. The model matches these observations with a Markov process of productivity shocks that features a standard deviation of 1.79 percent and the same first-order autocorrelation coefficient of 0.683 . 
Four sets of stochastic simulation results are presented below. The first set is for the NFE case in which the financial frictions have negligible effects. The second set is for the economy with binding margin requirements (BMR), for which the margin coefficient is set at $\kappa=0.005$. This simulation aims to illustrate the effects of the model's financial frictions in the absence of price guarantees. The third set introduces a simple price-guarantees policy that introduces a single, non-state-contingent guaranteed price (NSCG) for all dates and states of nature. The fourth set introduces the same guaranteed price but as a state-contingent guarantee (SCG) that applies only to those states of nature inside the "Sudden Stop region" of the BMR economy.

\subsection{Financial Frictions \& Sudden Stops without Price Guarantees}

The comparison between the NFE and BMR economies yields results analogous to those in Mendoza and Smith (2004). Hence, we focus the presentation of these results on the features of the comparison between the two economies that are relevant for studying the effects of price guarantees.

Figures 1a-1b show the ergodic distributions of equity and bonds in the NFE and BMR economies. The effect of the binding borrowing constraints is clear in the bonds distribution. This distribution has a marked bias to the left in the two economies but the distribution shifts markedly to the right when margin constraints bind. The opposite occurs with the distribution of equity. The distribution of equity is biased to the left in both economies, reflecting the inherent incentive that the risk-averse domestic agents have to sell equity to the risk-neutral foreign lenders. However, the binding margin constraints shift the equity distribution further to the left. This is the result of the equity "fire sales" in which domestic agents engage to meet margin calls.

The shifts in the ergodic distributions of equity and bonds also reflect the outcome of the precautionary savings effect. Domestic agents, aware of the imperfections of financial markets and the possibility of hitting binding borrowing limits, have an incentive to build up a buffer stock of savings in order to minimize the risk of being forced to reduce consumption abruptly. Hence precautionary savings

leads agents to increase their average holdings of risk-free bonds. As Table 1 shows, the long-run 
average of the bonds-output ratio increases from 18 percent in the NFE economy to 50 percent in the BMR economy.

Precautionary savings behavior also implies that agents will accumulate enough savings in the long run to lower the risk of facing states in which margin constraints actually bind. The long-run distribution of the BMR economy clearly rules out the states with the largest debt positions (in which a binding margin constraint would force the largest adjustments in consumption and the current account). Still, Table 1 shows that the long-run probability of facing a state of nature in which the margin constraint binds is about 4 percent. Thus, as Mendoza (2002) showed, the precautionary savings effect implies that Sudden Stops driven by occasionally binding credit constraints are rare but non-zero probability events in the long run. This also implies, however, that the effects of these constraints are hard to notice in the long-run business cycle moments computed with the ergodic distributions, as reported in Table 1. Hence, to analyze the model's ability to explain Sudden Stops we should study the short-run dynamics in the high-debt region of the state space in which the margin constraint binds. This region is referred to as the "Sudden Stop region."

The three-dimensional plots in Figures 2-4 are useful for identifying the Sudden Stop region. The plots show the responses of consumption, the current account-GDP ratio and equity prices on impact to a 1-standard-deviation negative shock to productivity for different combinations of the initial state of equity and bond holdings. These impact effects are measured as percent deviations from the long-run mean of each variable in the corresponding simulation. The Sudden Stop region of debt positions includes those values of $b$ that are low enough (i.e., high enough debt) for the margin constraint to be triggered. This region is easy to identify by comparing the plots for the NFE and BMR economies of each Figure.

Examining Figures 2-4, we observe that there are two key factors that determine the responses of consumption, the current account and asset prices in the Sudden Stop region: First, the leverage ratio (i.e. the ratio of debt to the market value of equity holdings). Second, the "liquidity" of the equity market (i.e., the difference between the initial equity position $\alpha$ at the time the margin calls begin and the lower bound on equity holdings $\chi$ ). As Mendoza and Smith (2004) showed, Sudden Stops with large consumption 
collapses and current account reversals occur when the leverage ratio is sufficiently high (see Figures 2 and 3). If the asset market is illiquid when the margin constraint binds (i.e., if the domestic agents' holdings of equity are near $\chi$ ), these Sudden Stops can feature negligible asset price declines because domestic agents have little or no equity that they can sell, and thus the fire sales in which they can engage are limited (see Figure 3). But if there is some liquidity in the asset market, Sudden Stops in consumption and the current account can be accompanied by a fall in asset prices. In contrast, when the leverage ratio is sufficiently low and domestic agents have highly liquid equity positions, the drop in consumption and the current account reversal are small (nearly as small as in the NFE case) but the drop in asset prices is relatively larger. In this case, domestic agents can liquidate more equity and thus trigger larger asset price collapses, but they do so in order to swap their limited borrowing ability in the bond market for equity sales so as to minimize the correction in consumption and the current account.

Mendoza and Smith showed that this pattern of larger current account corrections coinciding with smaller asset price collapses fits the observations of some emerging markets crises. In Mexico the current account reversal in the first quarter of 1995 was 5.2 percentage points of GDP but the drop in real equity prices was nearly 29 percent. By contrast, in Korea, the current account reversal in the first quarter of 1998 was twice as large, at 11 percentage points of GDP, but the asset price drop was just 10 percent.

To examine in more detail the short-run dynamics of Sudden Stops, we study the conditional forecasting functions of consumption, the current account-GDP ratio, and equity prices in response to a negative, one-standard-deviation productivity shock. These forecasting functions trace the non-linear impulse response functions of the variables conditional on initial positions of equity and bonds within the Sudden Stop region. Figures 5-6 plot two sets of forecasting functions, one for a "high leverage" state at which $\alpha=0.938$ and $b=-4.68$ (which imply a debt ratio of 60 percent of GDP and a leverage ratio of 3 percent of GDP), and one for a "low leverage" state with the same $\alpha$ but $b=-3.38$ (which imply a debt ratio of 43 percent of GDP and a leverage ratio of 2 percent of GDP). The plots show the forecasting functions for the four simulation scenarios (NFE, BMR, NSCG and SCG). 
As the charts in Figures 5-6 show, the responses to adverse productivity shocks in the NFE case are nearly identical in both the high and low leverage states. In contrast, the initial responses of the variables in the BMR economy differ sharply across the high and low leverage states, and also differ sharply from those of the NFE case. Figure 5 shows that, in the high leverage state of the BMR economy, the negative productivity shock triggers a Sudden Stop driven by the mechanisms described in Section 3. Domestic agents sell equity to meet margin calls and trigger a Fisherian deflation of equity prices that reduces further their ability to borrow. The net result is that, on impact, consumption and asset prices drop by about twice as much as in the NFE case and the current account deficit nearly vanishes, instead of widening to about 1.3 percent of GDP. Figure 6 shows that, in contrast, in the low leverage state domestic agents are better positioned to keep consumption smooth by substituting debt for equity as a way to finance a current account deficit. As a result, consumption and the current account respond by about the same magnitudes in both the NFE and BMR economies, but there is still a larger drop in equity prices in the latter.

Two important caveats about the data plotted in Figures 5 and 6. First, while the initial conditions used to generate the Figures were chosen to obtain outcomes that illustrate Sudden Stops, the universe of all the plausible impact effects that the model predicts for the Sudden Stop region (i.e., all the date-1 points for the set of forecasting functions conditional on all initial pairs $(\alpha, b)$ in this region) are shown in Figures 2-4. These Figures show that the Sudden Stop region includes scenarios with much larger consumption and current-account collapses than those shown in Figures 5 and 6, as well as scenarios in which the changes in the variables are virtually the same across the BMR and NFE cases. Second, the upward-slopping paths of the forecasting functions reflect the fact that the data produced by the model have not been filtered to remove low-frequency transitional dynamics. Since the bond and equity positions set as initial conditions for Figures 5 and 6 are significantly lower than their means in the ergodic distribution, the forecasting functions illustrate both the responses to the shock as well as the long-run dynamics of bonds and equity holdings. 
Figures 5-6 also show that Sudden Stops in this model are short-lived. The responses of consumption, the current account and equity prices in the BMR economy converge to the path of the NFE case in about 4 quarters. It may be possible to obtain stronger persistence effects by increasing the trading costs faced by foreign traders, so that they adjust their demand for equity more slowly. Another alternative not considered in the model could be to introduce endogenous capital accumulation. Mendoza (2004) shows that margin constraints can generate persistence in an environment in which firms incur adjustment costs in capital accumulation and margin constraints link the ability to borrow to the valuation of capital determined by Tobin's Q.

Kocherlakota (2000) showed that in analyzing the business cycle effects of credit constraints it is important to separate persistence from amplification. The forecasting functions can be misleading as a measure of amplification because they show deviations from the mean that do not take into account the second moments of the business cycle. Kocherlakota proposed to measure the amplification effect of a once-and-for-all, unanticipated linear income shock that triggers a credit constraint as the difference in a variable observed on impact as the shocks hits under the influence of the credit constraint relative to the variable's frictionless steady state in percent of the size of the shock. Here we take Mendoza's (2004) modification of this measure for a stochastic model in which the shocks follow a Markov process (and hence, in contrast to Kocherlakota's experiment, the shocks are "anticipated" and "recurrent"). The modified measure is the difference in the level of a variable between the BMR and the NFE economies in percent of the standard deviation of the variable in the NFE economy. For example, if the amplification coefficient of consumption for a negative productivity shock is 50 percent, it indicates that the fall in consumption in the BMR economy exceeds that of the frictionless economy by an amount equal to $1 / 2$ the magnitude of an "average" consumption cycle in the NFE case (i.e., the margin constraint amplifies business cycles in consumption by 50 percent).

The second and fourth columns of Table 2 report amplification effects for the high and low leverage states used in Figures 5-6. These amplification effects display a similar pattern as the forecasting functions. In the high leverage state, the amplification effects on consumption, the current 
account-GDP ratio, and equity prices are very large, at 61,70 and 342 percent respectively. In the low leverage state the amplification effects on consumption and the current account are negligible, at less than 3 percent, and the amplification effect on equity prices is weaker than in the high-leverage case, at 274 percent. Note that while Figures 5-6 show that the asset price effects of the margin constraint in terms of percent deviations from the mean are small, which is true by construction given the high elasticity of the foreign traders' demand function implied by the low value of $a$, the amplification effect is very large because it is a measure of the drop in asset prices in the BMR economy relative to the NFE case.

\subsection{Non-State-Contingent Price Guarantees}

Consider now the NSCG simulation with a non-state-contingent price guarantee. The guarantee is set $1 / 2$ of a percentage point above the "fundamentals" price in the low-productivity state of nature (i.e., the expected present value of dividends discounted at the world interest rate conditional on starting at date 0 with a negative shock to productivity). ${ }^{6}$ The fundamentals price is 2.185 , so the guaranteed price is set at 2.196 for all triples $(\alpha, b, \varepsilon)$ in the state space.

Figures 7a-7b show the ergodic distributions of equity and bonds for the NSCG and SCG economies. Relative to the BMR economy, the non-state-contingent guarantee shifts the distribution of equity markedly to the left and that of bonds to the right. The long-run average of the expected present value of excess prices (i.e., the long-run average of the $G($.$) function) is 0.01$, which is about $1 / 2$ of a percent above the mean equity price in the stochastic stationary state.

Comparing Panels I, II and III of Table 1, the most notable change is the reduction in the probability of hitting states with binding margin constraints. The price guarantee nearly rules out the possibility of hitting these states, compared to the 4-percent probability obtained in the BMR economy. The long-run moments of the model's endogenous variables vary slightly as the non-state-contingent price guarantee is added. The main changes are reduced consumption volatility and asset-price

\footnotetext{
${ }^{6}$ Setting a guaranteed price above the "fundamentals" price is not an awkward assumption because the "fundamentals" price as defined in the model does not correspond to the standard notion of a price in a frictionless environment. In the NFE case, asset markets are incomplete and risk-averse domestic agents trade equity with riskneutral foreign traders. Hence, equilibrium equity prices reflect the equity premium and the distortions induced by incomplete markets, and thus differ from the "fundamentals" price that discounts dividends at the risk-free rate.
} 
fluctuations that display less variability, persistence and co-movement with output in the NSCG economy relative to the NFE and BMR cases. The mean equity price increases by 0.053 percent, slightly more than the percent difference between the guaranteed price and the fundamentals price of the low productivity state. The coefficient of variation of consumption falls by about $1 / 5$ of a percentage point, the variability of the current account and the trade balance increase slightly and that of equity prices falls slightly. Consumption and equity prices also become less correlated with GDP, and the first-order autocorrelation of equity prices does fall markedly from about 0.61 to 0.38 .

The effects of the price guarantee on Sudden Stop dynamics and amplification effects for the high and low leverage states are shown in Figures 5-6 and Table 2. These results show that the guarantee is an effective policy for preventing Sudden Stops. Comparing the NSCG and BMR economies, the high leverage state shown in Figure 5 shows that the guarantee reduces the initial drop in consumption and current account reversal, and prevents the drop in equity prices (turning it into a small increase of about $1 / 4$ of a percentage point). Figure 6 shows that in the low leverage state the increase in equity prices is larger, and we now obtain an initial increase in consumption and a widening of the current account deficit slightly larger than in both the BMR and NFE cases. Comparing the NSCG and BMR economies, the price guarantee increases the initial price of equity by $0.66 \%$ in both the high and low leverage states. Yet, foreign traders still execute the price guarantee in both states because the guaranteed price at 2.196 exceeds these higher prices.

Table 2 shows that amplification effects in the high leverage state of the NSCG economy fall sharply relative to those of the BMR economy (61 to 39 percent for consumption, 70 to 44 percent for the current account and 342 to 214 percent for asset prices). In the low leverage state, the coefficients of amplification increase slightly. However, since these coefficients are reported in absolute value, the small increase hides the fact that consumption, the current account deficit, and asset prices are actually increasing, rather than falling, in the economy with the non-state contingent guarantee.

Figure 8 plots the levels of equity prices in the low productivity state for the NFE, BMR and NSCG economies in the entire state space of equity and bond positions. The plots show that the price 
guarantee not only results in higher prices in the Sudden Stop region, but it actually results in higher prices in virtually all states. In fact, the guarantee has its largest effect on asset prices in states well outside the Sudden Stop region. Asset prices in this region are significantly higher in the NSCG economy than in either the NFE or BMR economies. This is a potentially important drawback of a policy that sets non-state-contingent price guarantees: it leads to distortions on asset prices even when the economy is in states in which it is very far from being exposed to the risk of Sudden Stops. In this situation, the tradeoff between managing financial frictions v. fueling moral hazard may tilt toward the latter.

\subsection{State-Contingent Price Guarantees}

One obvious alternative to remedy the drawbacks of a policy of non-state-contingent price guarantees is to consider state-contingent guarantees. This last set of results study this option by examining the results of the SCG economy. This economy features a price guarantee set at the same level as in the NSCG case but applying it only to the states of nature inside the Sudden Stop region. In particular, the guaranteed price of 2.196 is offered only in the states of nature that include all combinations of the first 25 nodes of the bonds grid (i.e., the largest debt positions), the 72 points of the equity grid and the two realizations of the Markov vector of productivity shocks.

Figures 7a-7b show that the SCG economy yields a long-run distribution of equity holdings that is less skewed to the left, while the opposite occurs with the long-run distribution of bonds. Table 1 shows that the changes in the long-run business cycle moments of the SCG economy relative to the NFE and BMR cases are qualitatively similar to those noted for the NSCG economy, although the magnitude of the changes is smaller. There is one important exception: the SCG economy still features near-zero percent probability of observing states of nature in which the margin constraint binds. Hence, the statecontingent guarantees are as effective as the non-state-contingent guarantee at eliminating the possibility of hitting states with binding margin requirements in the long run.

Figures 5 and 6 show that, in both the high and low leverage states, the SCG economy features nearly-identical initial responses in consumption and the current account and a smaller recovery in asset prices as the NSCG economy. The SCG economy converges faster to mimic the dynamic paths of the 
NFE economy. In line with these results, the amplification coefficients for the SCG economy show qualitatively similar, but quantitatively smaller, changes when compared to those for the BMR economy as those obtained when making the comparison between the NSCG and BMR economies.

Finally, a comparison of the middle and bottom plots of Figure 8 shows that the SCG economy yields higher asset prices mainly in the Sudden Stop region of the state space. Thus, the policy of state contingent guarantees induces smaller distortions on asset demand and asset prices than the non-statecontingent guarantees, particularly outside the Sudden Stop region, yet it seems to produce similar effects in terms of its ability to prevent Sudden Stops.

\section{Conclusions}

The equilibrium asset pricing theory presented in this paper suggests that, if global capital markets are distorted by collateral constraints and asset trading costs, an arrangement to provide ex ante price guarantees on the emerging markets asset class could be an effective means to contain Sudden Stops in emerging economies. The same theory predicts, however, that introducing these guarantees creates an additional distortion that induces a moral hazard effect propping up the demand for emerging markets assets of foreign investors. Hence, the provision of ex ante price guarantees creates a tradeoff between the benefits that can be gained by undoing the distortions caused by imperfections in world capital markets and the costs that result from the moral hazard effect. This cost-benefit analysis involves quantitative comparisons of equilibrium outcomes across distorted economies with incomplete asset markets that can only be performed via numerical simulation analysis.

The model studied in this paper borrows from Mendoza and Smith (2004) the setup of a dynamic, stochastic general equilibrium model of emerging-markets asset prices in which collateral constraints and asset trading costs generate Sudden Stops, and thus justify the use price guarantees. Collateral constraints are modeled in the form of a margin constraint that limits the ability of domestic agents to leverage foreign debt on equity holdings. Asset trading costs are incurred by foreign traders and take the form of per-trade costs and recurrent costs paid each period regardless of trading activity. In this environment, adverse shocks that hit an economy with a sufficiently high stock of debt relative to the market value of 
equity trigger margin calls. These margin calls lead to a fire sale of equity by domestic agents and a Fisherian deflation of asset prices. If domestic asset markets are relatively illiquid, the result is a Sudden Stop with a collapse in consumption, a reversal in the current account and a fall in asset prices.

The Mendoza-Smith model is modified in this paper to introduce an IFO that offers foreign traders ex ante guarantees on the price of the equity of the emerging economy, financing the cost of any realized guarantees by levying a lump sum tax on foreign traders. These guarantees introduce a distortion that leads foreign traders to increase their demand for emerging markets assets. This distortion can be interpreted as a valuation effect that adds to the "fundamentals price" the conditional expected present discounted value of the excess of guaranteed prices over market prices that traders expect in the future along the stochastic equilibrium path.

The challenge to the IFO is to design the price guarantees so that they can deliver an outcome that improves over the outcome obtained when there is no policy in place to contain Sudden Stops triggered by financial frictions. Our quantitative analysis applied to the case of Mexico illustrates the complexity of this task. Part of the challenge is that an effective system of ex ante price guarantees requires a good model of asset prices (i.e., a model that can start by explaining the observed features of Sudden Stops without price guarantees and that can then be used to assess the effects of the guarantees). The model we proposed in this paper is consistent with the qualitative features of Sudden Stops but its ability to match some of the quantitative features of the data, particularly the magnitude of the collapse in asset prices, is limited. Yet, the quantitative results suggest that a system of price guarantees can go a long way in containing the collapses in consumption and current account reversals of Sudden Stops. Non-state contingent guarantees have the drawback that they induce strong moral-hazard-like distortions on asset prices that can lead to significant "over-valuation" of an emerging economy's assets (i.e., prices higher than those that would prevail free of these distortions driven by financial frictions). We showed, however, that state contingent guarantees can help reduce the moral hazard distortion and still be of help at preventing Sudden Stops. 
We focused the comparison of outcomes across economies with and without price guarantees on the prices and allocations of the corresponding equilibria, and refrained from making comparisons in terms of welfare effects. The reason is that in essence the model we examined is one in which access to credit markets is used to smooth consumption, and it is well known that the cost of giving up access to world credit markets in this class of models is negligible (see Mendoza (1991)). Our welfare calculations do show that the economies with price guarantees dominate the economy without them, even if in absolute terms the welfare gains are always small. For example, the last row of Table 2 shows that lifetime utility in the high leverage state of an economy with non-state contingent guarantees dominates that of the economy with binding margin requirements by the equivalent of a 0.023 percent increase in a stationary consumption path.

Non-trivial difficulties would remain in designing an ideal schedule of ex ante price guarantees even if the model could mimic the observed quantitative features of Sudden Stops. The effects of price guarantees are driven by forward looking elements that depend on agents' expectations of the likelihood of executing price guarantees and/or hitting Sudden Stops in the future (even if at present no price guarantees are executed and the economy has access to foreign financing). Hence, to be effective at using price guarantees to contain Sudden Stops without creating strong moral hazard effects, the IFO needs to be able to determine the range of debt and equity values at which Sudden Stops occur and the crash prices that Sudden Stops produce, as well as the "normal" levels of asset prices that would prevail in a frictionless world without margin constraints and trading costs. This paper makes some progress in reaching these objectives, but clearly there is a lot left for further research. 


\section{References}

Arellano, Cristina and Enrique G. Mendoza (2003), "Credit Frictions and 'Sudden Stops' in Small Open Economies: An Equilibrium Business Cycle Framework for Emerging Markets Crises," in Dynamic Macroeconomic Analysis” S. Altug, J. Chadha and C. Nolan eds., Cambridge Univ. Press, Cambridge.

Aiyagari, S. Rao and Mark Gertler (1999), "Overreaction of Asset Prices in General Equilibrium," Review of Economic Dynamics.

Auenhaimer, Leonardo and Roberto Garcia-Saltos (2000), "International Debt and the Price of Domestic Assets, " IMF Working Paper 00/177

Caballero, Ricardo J. ad Arvind Krishnamurthy (2001), "International and Domestic Collateral Constraints in a Model of Emerging Market Crises," Journal of Monetary Economics, v.48, 513-548.

Calvo, Guillermo A. (2002), "Globalization Hazard and Delayed Reform in Emerging Markets," mimeo, Center for International Economics, Department of Economics, University of Maryland.

(2000), "Balance of Payments Crises in Emerging Markets: Large Capital Inflows and Sovereign Governments.” In Currency Crises, Paul Krugman ed. Chicago: University of Chicago Press.

(1998), "Capital Flows and Capital-Market Crises: The Simple Economics of Sudden Stops," Journal of Applied Economics, v.1, pp 35-54.

, and Allan Drazen (1998), "Uncertain Duration of Reform: Dynamic Implications,"

Macroeconomic Dynamics.

, and Carmen M. Reinhart (1999), "When Capital Inflows come to a Sudden Stop: Consequences and Policy Options," mimeo, Center for International Economics, Department of Economics, University of Maryland.

, and Enrique G. Mendoza (1996), "Mexico's Balance of Payments Crises: A Chronicle of a Death Foretold," Journal of International Economics, v. 41, pp. 235-264.

, and Enrique G. Mendoza (2000a), "Capital-Market Crises and Economics Collapse in Emerging

Markets: An Informational-Frictions Approach,” American Ec. Review: Papers \& Proceedings, May.

, and Enrique G. Mendoza (2000b), "Rational Contagion and the Globalization of Securities

Markets," Journal of International Economics, v.51.

Epstein Larry G. (1983), "Stationary Cardinal Utility and Optimal Growth under Uncertainty," Journal of Economic Theory, 31, 133-152.

Frankel, Jeffrey and Sebastian Edwards (2002), Preventing Currency Crises in Emerging Markets. A National Bureau of Economic Research Conference Report. Chicago: University of Chicago Press.

Fisher, Irving (1993), “The Debt-Deflation Theory of Great Depressions,” Econometrica 1, 337-57.

Greenwood, Jeremy, Zvi Hercowitz and Gregory W. Huffman (1988), "Investment, Capacity Utilization and the Real Business Cycle", American Economic Review, June. 
International Monetary Fund (1999), International Capital Markets, September, International Monetary Fund, Washington:DC.

Izquierdo, Alejandro (2000) "Credit Constraints, and the Asymmetric Behavior of Asset Prices and Output under External Shocks,” mimeo, The World Bank. June.

Kiyotaki, Nobuhiro and John Moore (1997), "Credit Cycles," Journal of Political Economy, v.105, 211248.

Kocherlakota, Narayana (2000) "Creating Business Cycles Through Credit Constraints," Federal Reserve Bank of Minneapolis Quarterly Review, v. 24, no. 3, Summer, 2-10.

Lerrick, Adam, and Allan H. Meltzer (2001), "Blueprint for and International Lender of Last Resort," mimeo, Carnegie Mellon University.

Ljungqvist, Lars (2000) “Government Guarantees on Assets and Volatility," mimeo, Stockholm School of Economics.

Ljungqvist, Lars , and Thomas J. Sargent (2000), Recursive Macroeconomic Theory, Boston: MIT Press.

Mendoza, Enrique G. (1991), "Capital Controls and the Dynamic Gains from Trade in a Business Cycle Model of a Small Open Economy," IMF Staff Papers, September.

, (2002), "Credit, Prices, and Crashes: Business Cycles with a Sudden Stop.” In Preventing Currency Crises in Emerging Markets, Frankel, Jeffrey and Sebastian Edwards eds. Chicago: University of Chicago Press.

, and Katherine A. Smith (2004), "Margin Calls, Trading Costs and Asset Prices in Emerging Markets: the Financial Mechanics of the 'Sudden Stop' Phenomenon," mimeo, Department of Economics, University of Maryland.

(2004), “'Sudden Stops' in an Equilibrium Business Cycle Model with Credit Constraints: A Fisherian Deflation of Tobin's q," mimeo, Department of Economics, University of Maryland.

Milesi-Ferreti, Gian Maria, and Assaf Razin (2000), "Current Account Reversals and Currency Crises:Empirical Regularities.” In Currency Crises, Paul Krugram ed. Chicago: University of Chicago Press.

Paasche, Bernhard (2001), "Credit Constraints and International Financial Crises," Journal of Monetary Economics, v.28, 623-650.

Schneider, Martin and Aron Tornell (1999), "Lending Booms, Asset Price Inflation and Soft Landings," mimeo, Department of Economics, University of California at Los Angeles.

Valderrama, Diego (2003), "The Impact of Financial Frictions on a Small Open Economy: When Current Account Borrowing Hits a Limit," mimeo, Research Department, Federal Reserve Bank of San Francisco. 
Table 1. Long Run Business Cycle Moments

\begin{tabular}{|c|c|c|c|c|c|}
\hline variable & mean & $\begin{array}{c}\text { standard } \\
\text { deviation } \\
\text { (in percent) }\end{array}$ & $\begin{array}{c}\text { standard } \\
\text { deviation } \\
\text { relative to GDP }\end{array}$ & $\begin{array}{l}\text { correlation } \\
\text { with } \\
\text { GDP }\end{array}$ & $\begin{array}{l}\text { first-order } \\
\text { autocorrelation }\end{array}$ \\
\hline \multicolumn{6}{|l|}{ I. Nearly Frictionless Economy } \\
\hline GDP & 7.833 & 2.644 & 1.000 & 1.000 & 0.683 \\
\hline consumption & 5.366 & 2.185 & 0.826 & 0.853 & 0.770 \\
\hline current account-GDP ratio & 0.000 & 1.347 & 0.509 & 0.979 & 0.660 \\
\hline trade balance-GDP ratio & 0.315 & 0.948 & 0.358 & 0.564 & 0.811 \\
\hline equity price & 2.187 & 0.121 & 0.046 & 0.961 & 0.606 \\
\hline foreign debt-GDP ratio & 0.177 & 56.694 & 21.442 & -0.076 & 0.997 \\
\hline debt-equity ratio & 0.010 & 2.888 & 1.092 & 0.000 & 0.001 \\
\hline \multicolumn{6}{|l|}{ II. Economy with Financial Frictions } \\
\hline GDP & 7.833 & 2.644 & 1.000 & 1.000 & 0.683 \\
\hline consumption & 5.365 & 2.186 & 0.827 & 0.856 & 0.771 \\
\hline current account-GDP ratio & 0.000 & 1.324 & 0.501 & 0.982 & 0.664 \\
\hline trade balance-GDP ratio & 0.315 & 0.940 & 0.355 & 0.565 & 0.823 \\
\hline equity price & 2.187 & 0.121 & 0.046 & 0.962 & 0.609 \\
\hline foreign debt-GDP ratio & 0.499 & 37.964 & 14.358 & -0.118 & 0.994 \\
\hline debt-equity ratio & 0.026 & 2.007 & 0.759 & 0.000 & 0.001 \\
\hline long run prob of binding mar. const (in \%) & 3.973 & & & & \\
\hline \multicolumn{6}{|l|}{$\begin{array}{l}\text { III. Economy with Financial Frictions \& } \\
\text { Non-state Contingent Guarantees }\end{array}$} \\
\hline GDP & 7.833 & 2.644 & 1.000 & 1.000 & 0.683 \\
\hline consumption & 5.362 & 2.052 & 0.776 & 0.790 & 0.724 \\
\hline current account-GDP ratio & 0.000 & 1.487 & 0.562 & 0.968 & 0.660 \\
\hline trade balance-GDP ratio & 0.315 & 1.111 & 0.420 & 0.631 & 0.750 \\
\hline equity price & 2.198 & 0.099 & 0.037 & 0.891 & 0.384 \\
\hline foreign debt-GDP ratio & 1.336 & 41.053 & 15.526 & 0.001 & 0.992 \\
\hline debt-equity ratio & 0.071 & 2.186 & 0.827 & 0.000 & 0.006 \\
\hline long run prob of binding mar. const (in \%) & 0.001 & & & & \\
\hline \multicolumn{6}{|l|}{$\begin{array}{l}\text { IV. Economy with Financial Frictions \& } \\
\text { State Contingent Guarantees }\end{array}$} \\
\hline GDP & 7.833 & 2.644 & 1.000 & 1.000 & 0.683 \\
\hline consumption & 5.364 & 2.121 & 0.802 & 0.834 & 0.765 \\
\hline current account-GDP ratio & 0.000 & 1.380 & 0.522 & 0.974 & 0.660 \\
\hline trade balance-GDP ratio & 0.315 & 1.000 & 0.378 & 0.599 & 0.788 \\
\hline equity price & 2.188 & 0.121 & 0.046 & 0.903 & 0.630 \\
\hline foreign debt-GDP ratio & 1.114 & 34.141 & 12.912 & -0.067 & 0.991 \\
\hline debt-equity ratio & 0.059 & 1.810 & 0.685 & 0.000 & 0.004 \\
\hline long run prob of binding mar. const (in \%) & 0.001 & & & & \\
\hline
\end{tabular}


Table 2. Initial Amplification of a Negative Productivity Shock and Welfare Effects

\begin{tabular}{|c|c|c|c|c|c|c|}
\hline \multirow[b]{2}{*}{ Variable } & \multicolumn{3}{|c|}{ high leverage state* (alpha $=0.938, b=-4.68)$} & \multicolumn{3}{|c|}{ low leverage state $* *(a l p h a=0.938, b=-3.38)$} \\
\hline & $\begin{array}{l}\text { financial } \\
\text { frictions }\end{array}$ & $\begin{array}{c}\text { fin. fric. \& } \\
\text { non-s.c. } \\
\text { guarantees }\end{array}$ & $\begin{array}{l}\text { fin. fric. \& } \\
\text { s.c. guarantees }\end{array}$ & $\begin{array}{l}\text { financial } \\
\text { frictions }\end{array}$ & $\begin{array}{l}\text { fin. fric. \& } \\
\text { non-s.c. } \\
\text { guarantees }\end{array}$ & $\begin{array}{l}\text { fin. fric. \& } \\
\text { s.c. guarantees }\end{array}$ \\
\hline \multicolumn{7}{|c|}{ amplification effects (in absolute value) } \\
\hline Consumption & 0.611 & 0.385 & 0.436 & 0.025 & 0.162 & 0.133 \\
\hline $\begin{array}{l}\text { Current account- } \\
\text { GDP ratio }\end{array}$ & 0.697 & 0.439 & 0.497 & 0.029 & 0.184 & 0.152 \\
\hline Equity price & 3.419 & 2.142 & 0.886 & 2.737 & 2.865 & 2.006 \\
\hline \multicolumn{7}{|c|}{$\begin{array}{l}\text { welfare effects (percent change in utility-equivalent stationary consumption level relative to } \\
\text { nearly frictionless economy) }\end{array}$} \\
\hline Welfare & -0.006 & 0.017 & 0.005 & -0.003 & 0.019 & 0.006 \\
\hline
\end{tabular}

*Debt-equity ratio of -2.9 percent and debt/GDP ratio of -59.7 percent.

$* *$ Debt-equity ratio of -2.1 percent and debt/GDP ratio of -43.1 percent. 
Figure 1a. Ergodic Distributions of Domestic Equity Holdings

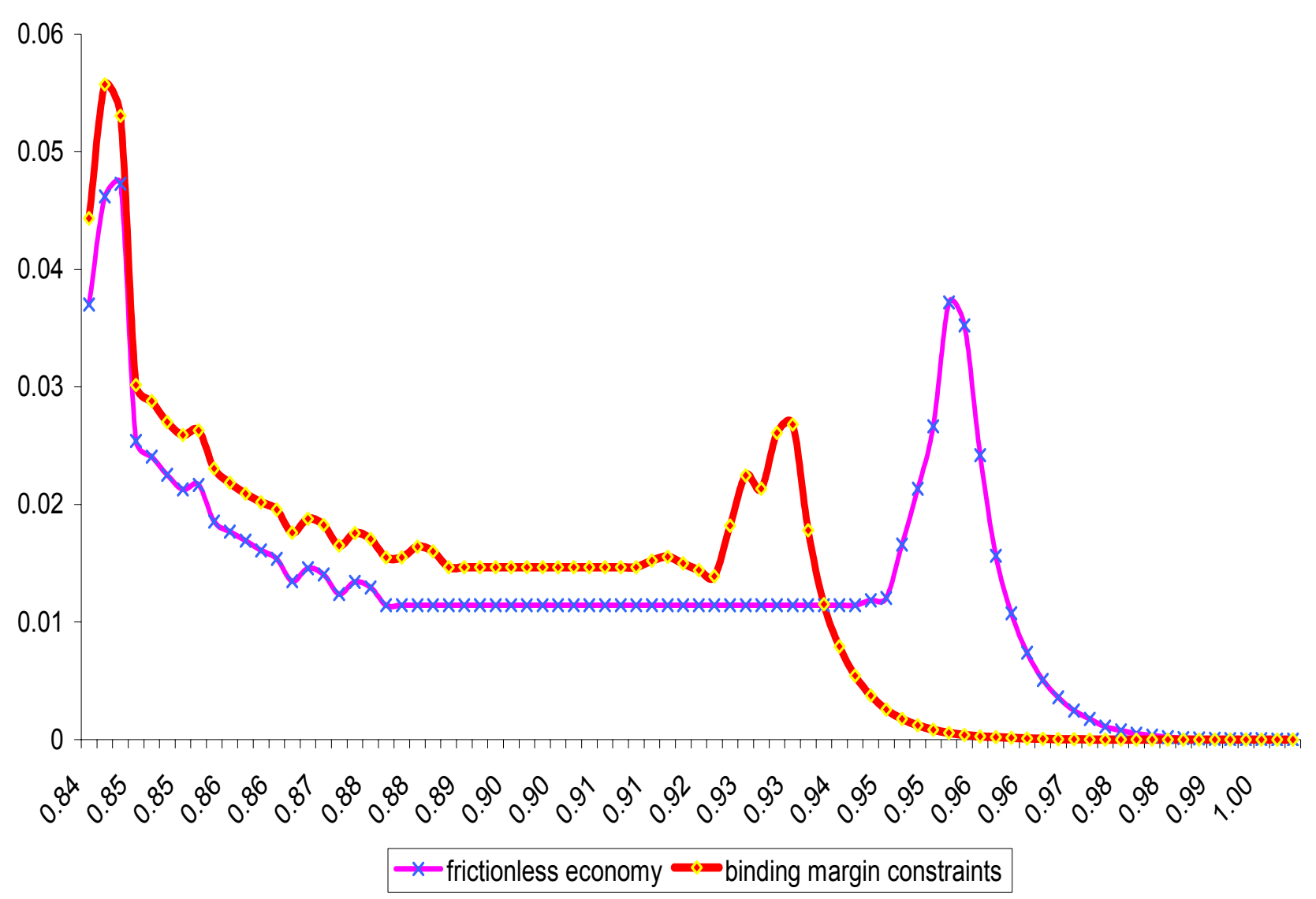


Figure 1b. Ergodic Distributions of Bonds

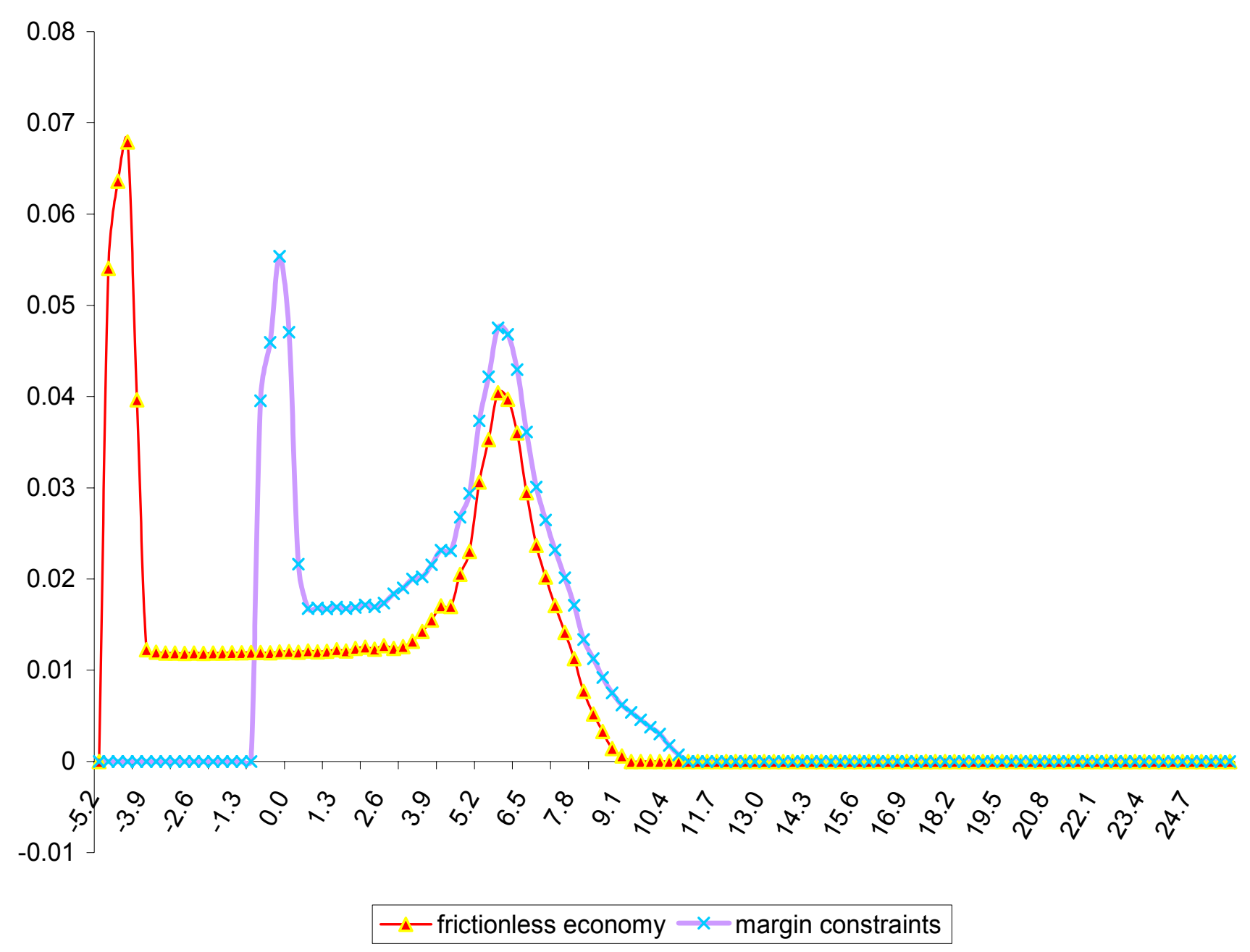


Figure 2. Consumption Impact Effects of a Negative Productivity Shock for the Universe of Initial Equity \& Bond Positions (percent deviations from long run average)

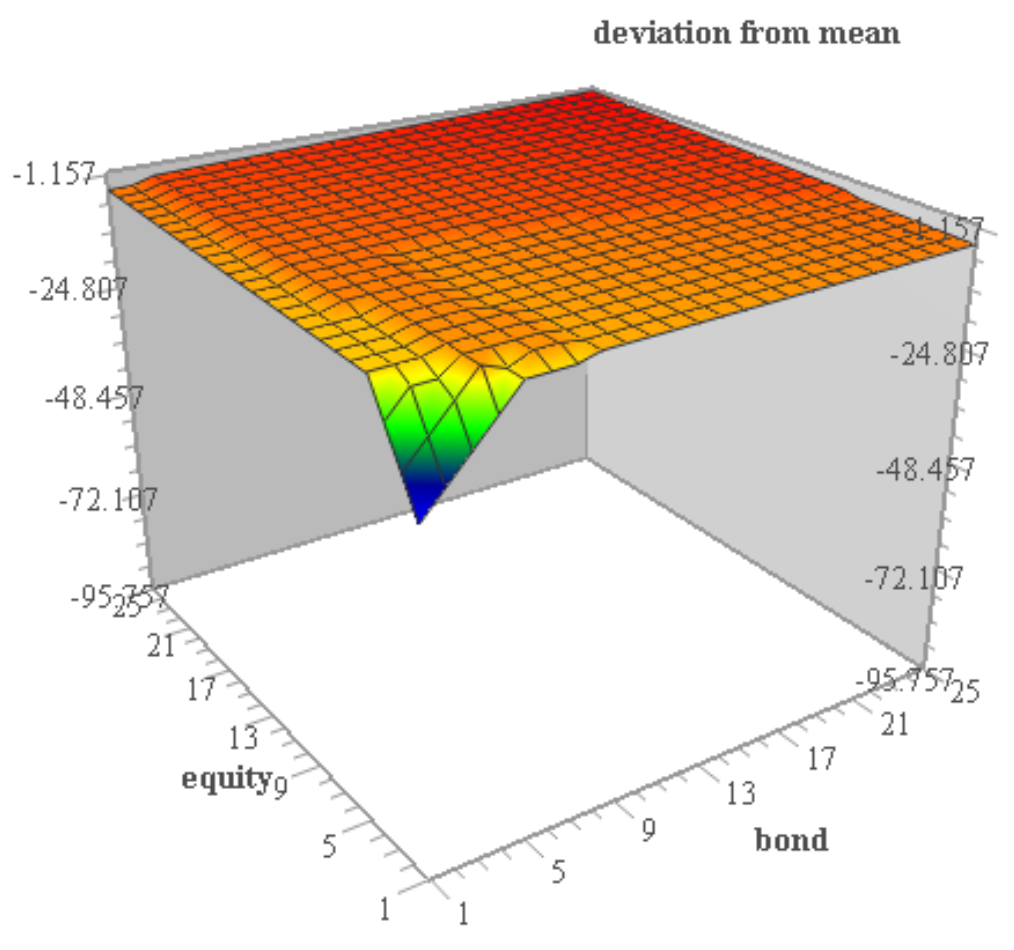

a. Nearly Frictionless Economy

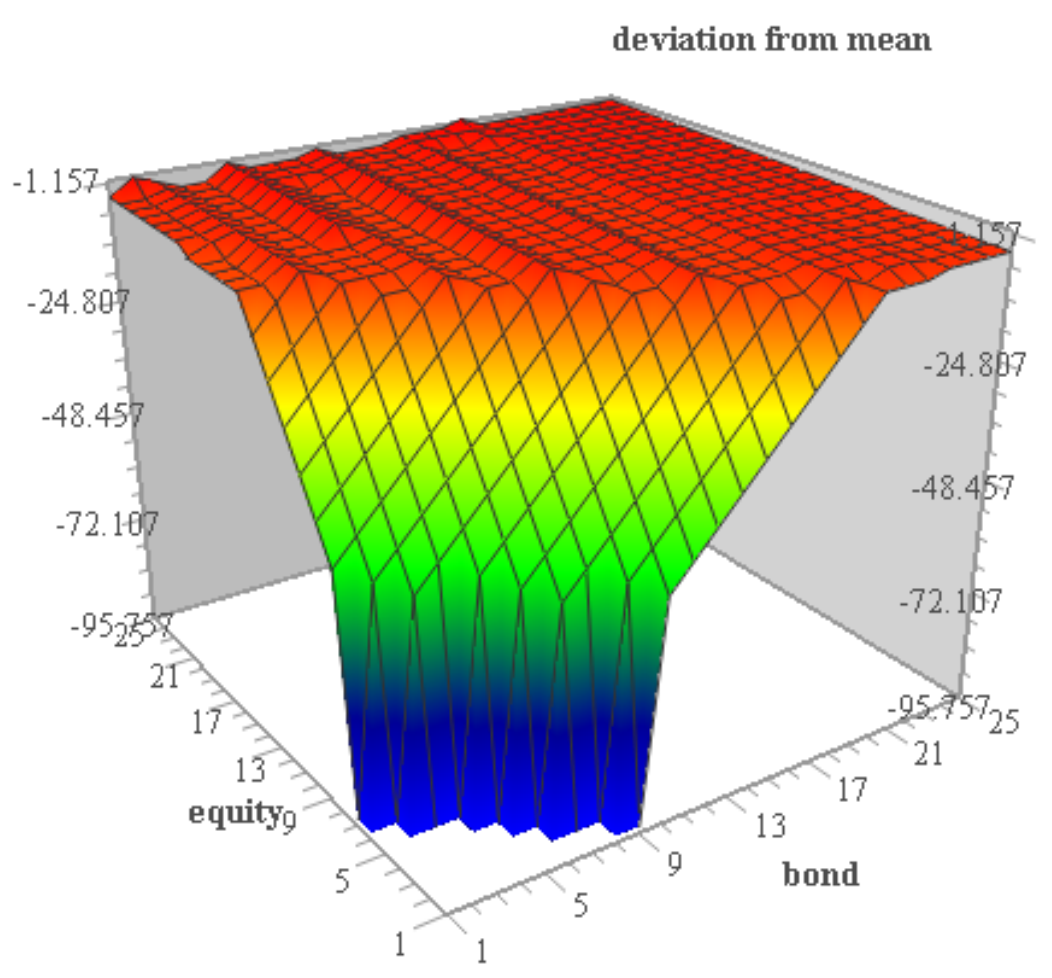

b. Economy with Financial Frictions 
Figure 3. Current Account-Output Ratio Impact Effects of a Negative Productivity Shock for the Universe of Initial Equity \& Bond Positions (percent deviations from long run average)

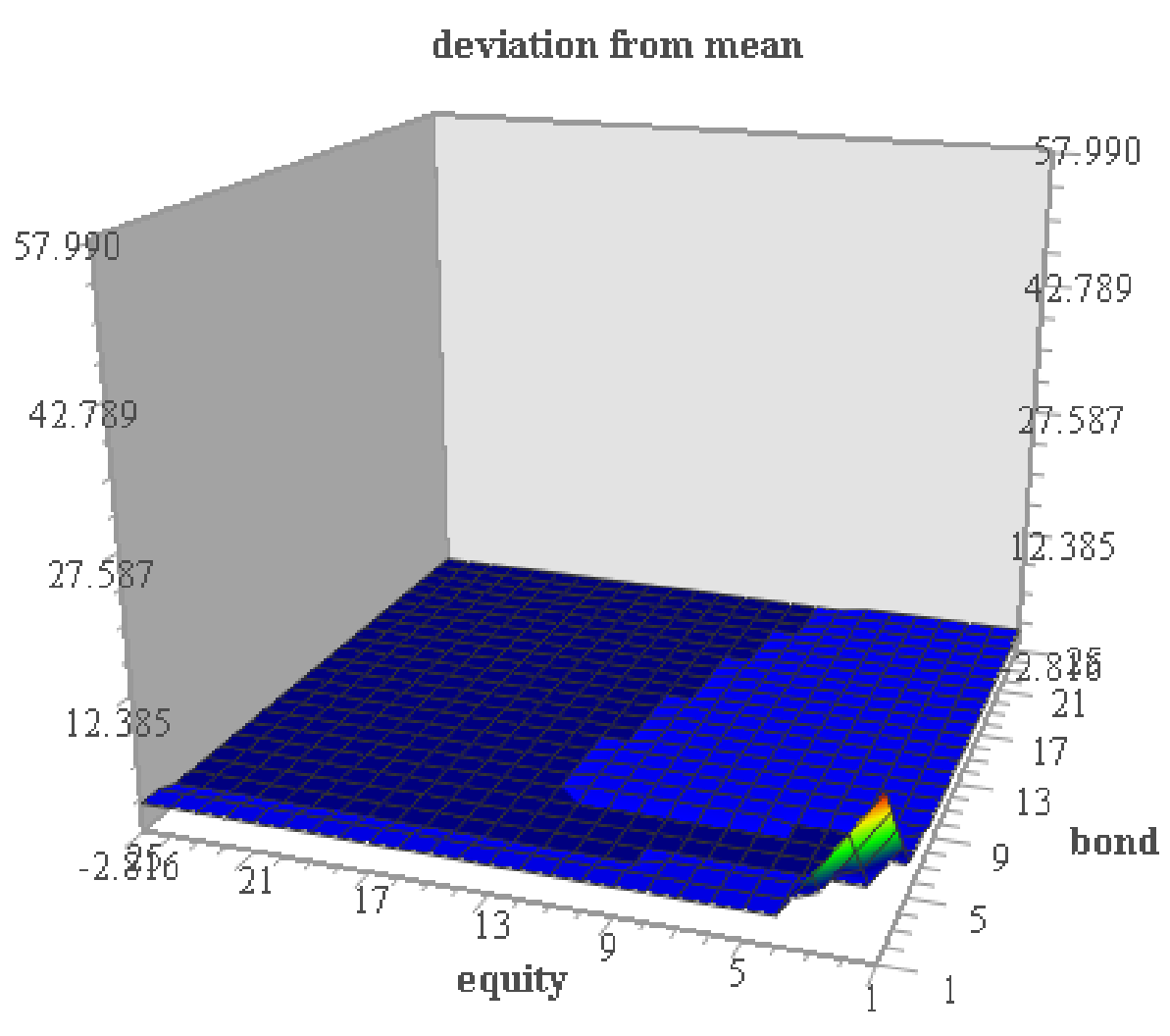

a. Nearly Frictionless Economy

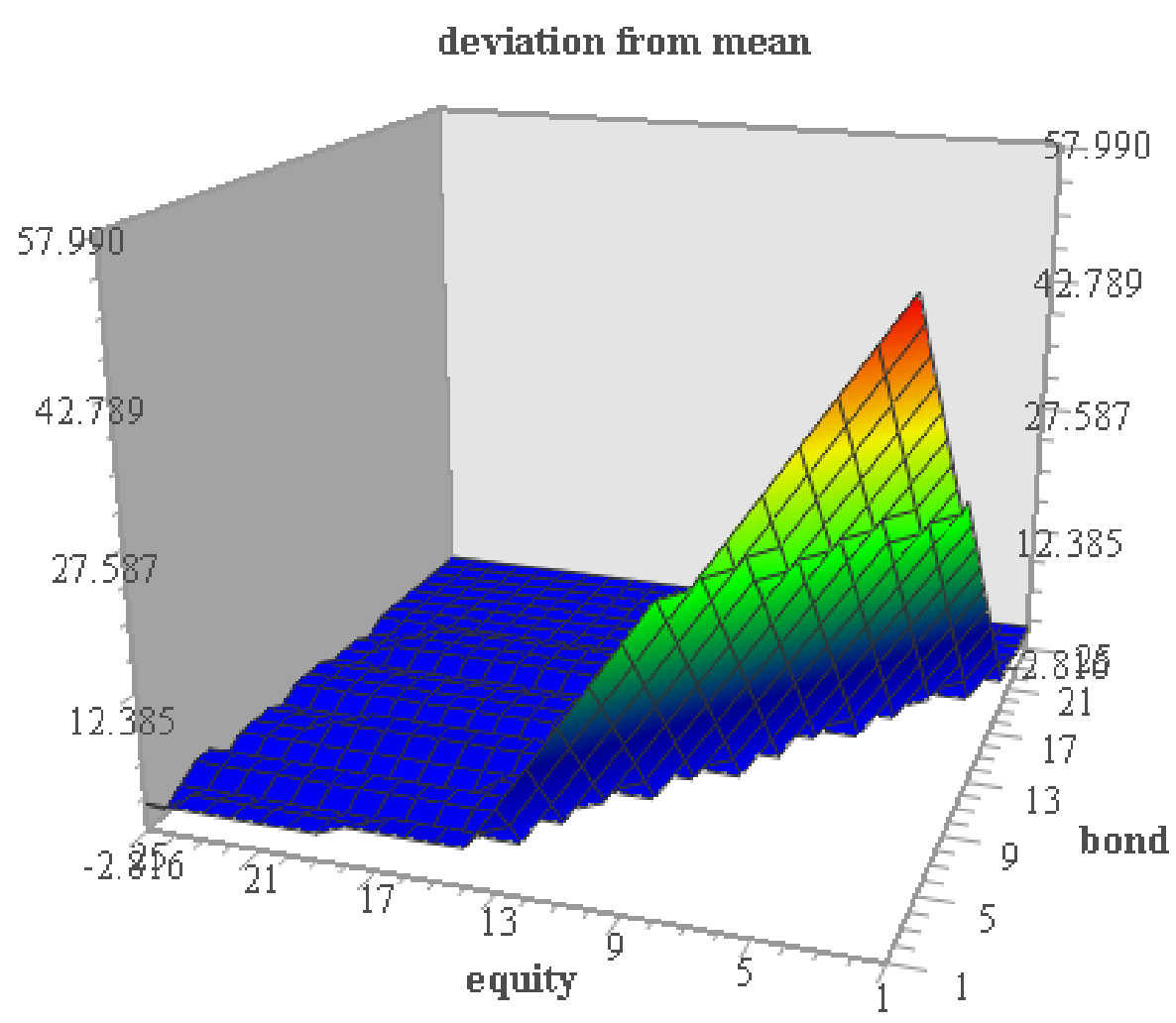

b. Economy with Financial Frictions 
Figure 4. Equity Price Impact Effects of a Negative Productivity Shock for the Universe of Initial Equity \& Bond Positions (percent deviations from long run average)

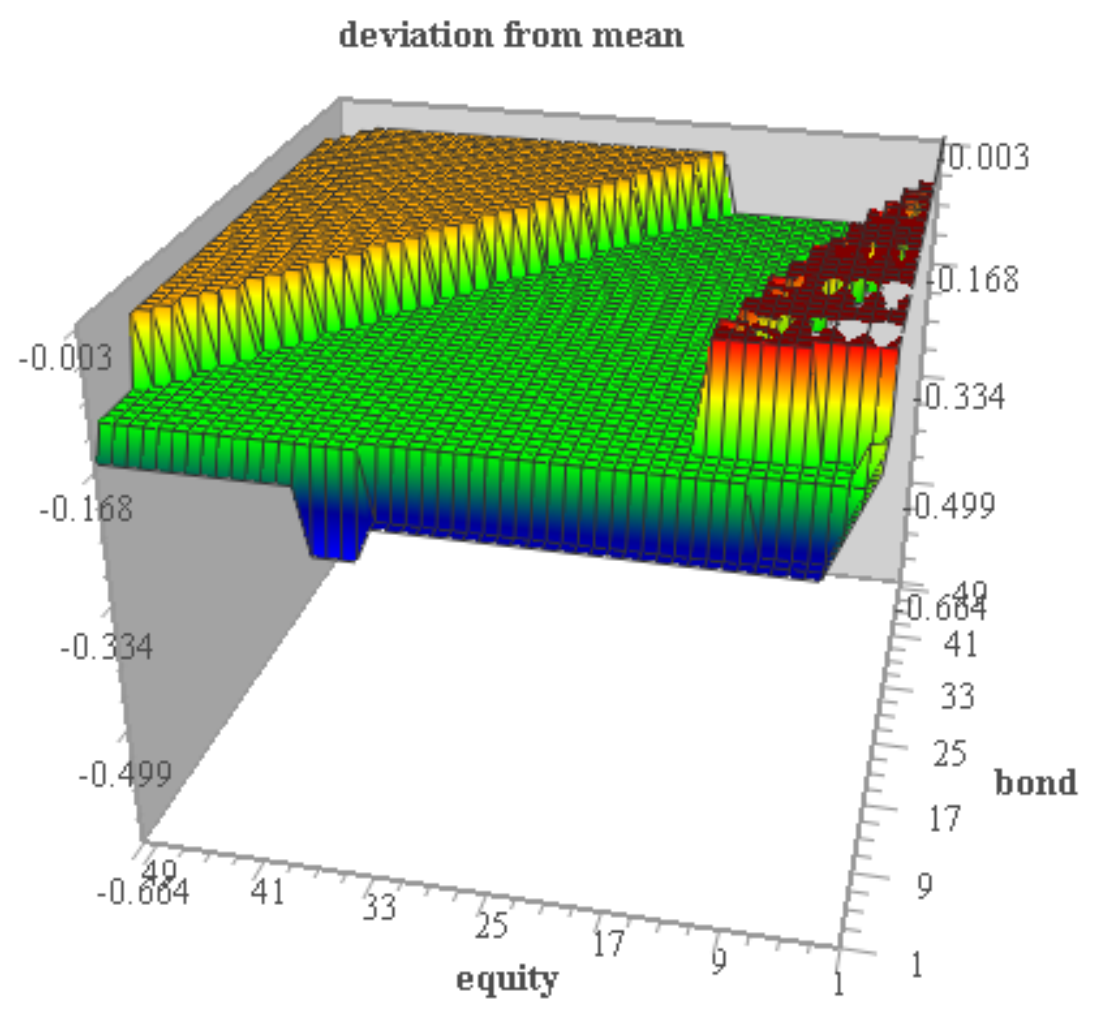

a. Nearly Frictionless Economy

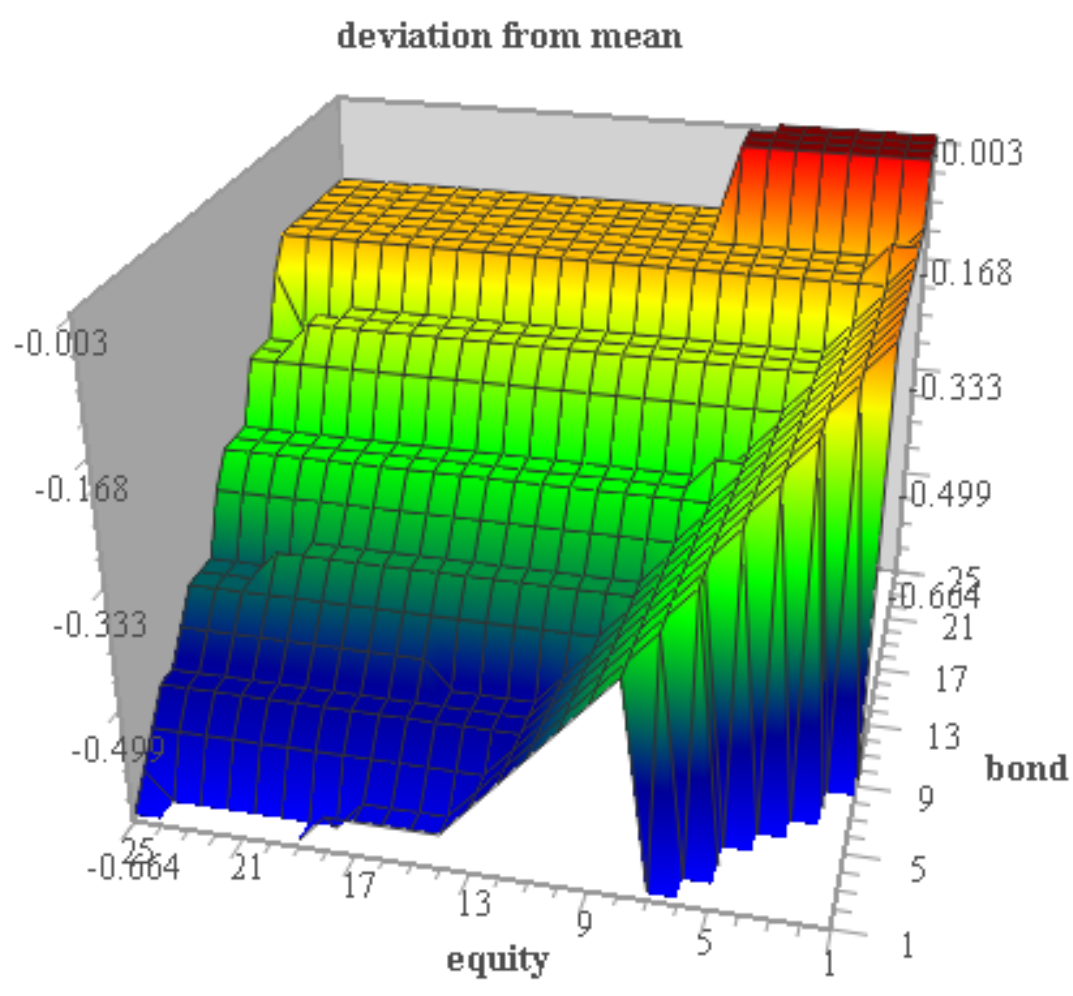

b. Economy with Financial Frictions 
Figure 5. Conditional Forecasting Functions in Response to Low Productivity Shock in High Leverage State

\section{Consumption}

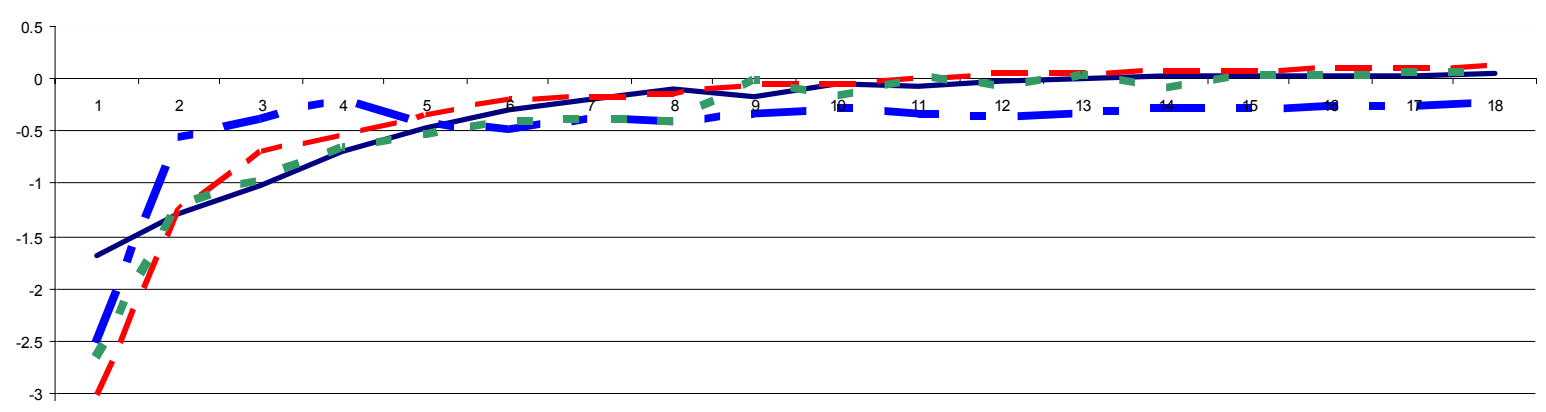

Equity Price

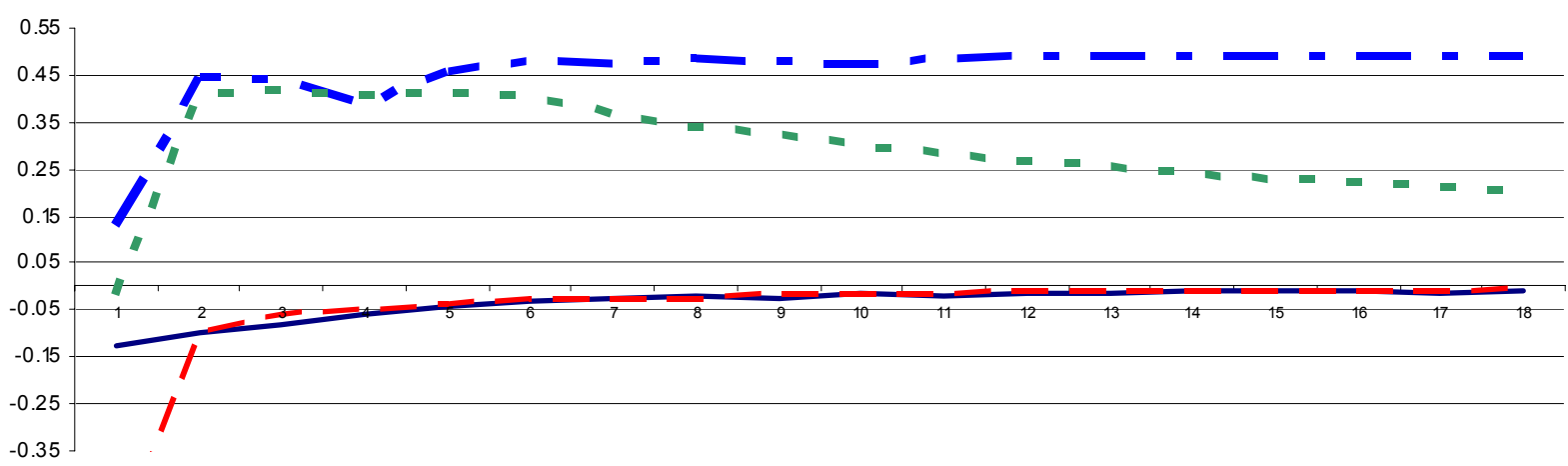

\section{Current Account-GDP Ratio}

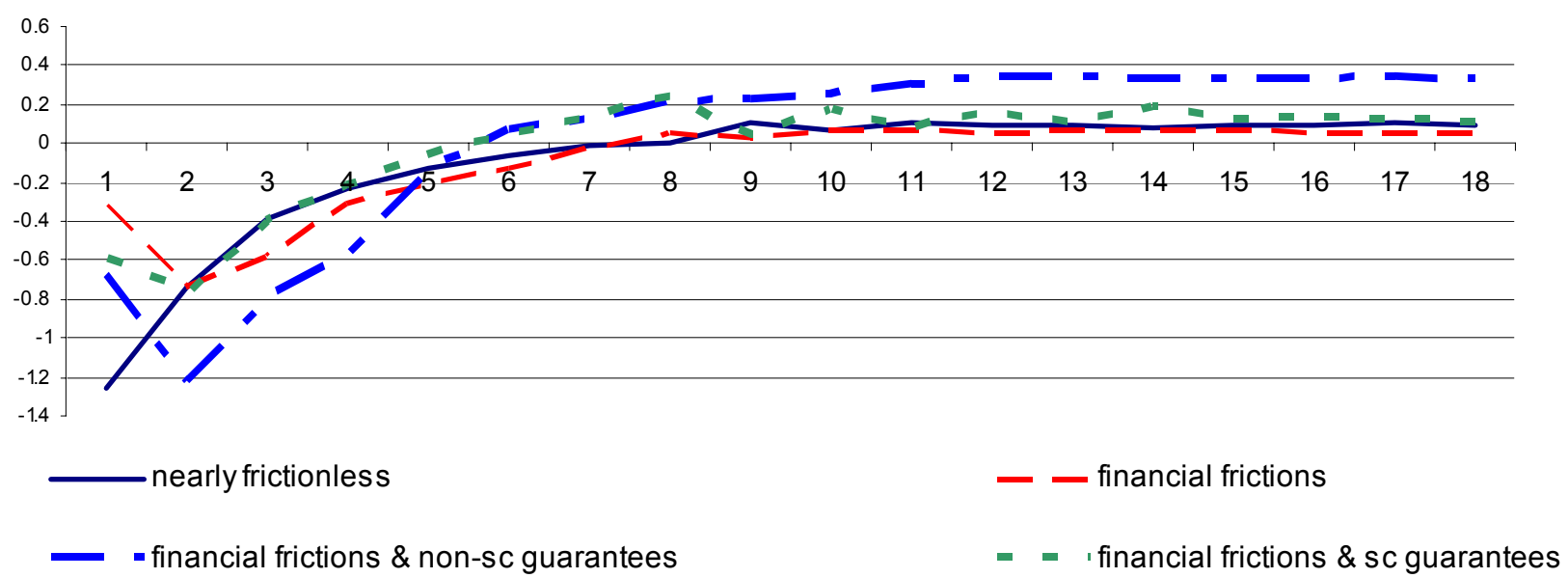

Note: forecasting functions are conditional on initial states alpha $=0.938, b=-4.68$ 
Figure 6. Conditional Forecasting Functions in Response to Low Productivity Shock in Low Leverage State

\section{Consumption}

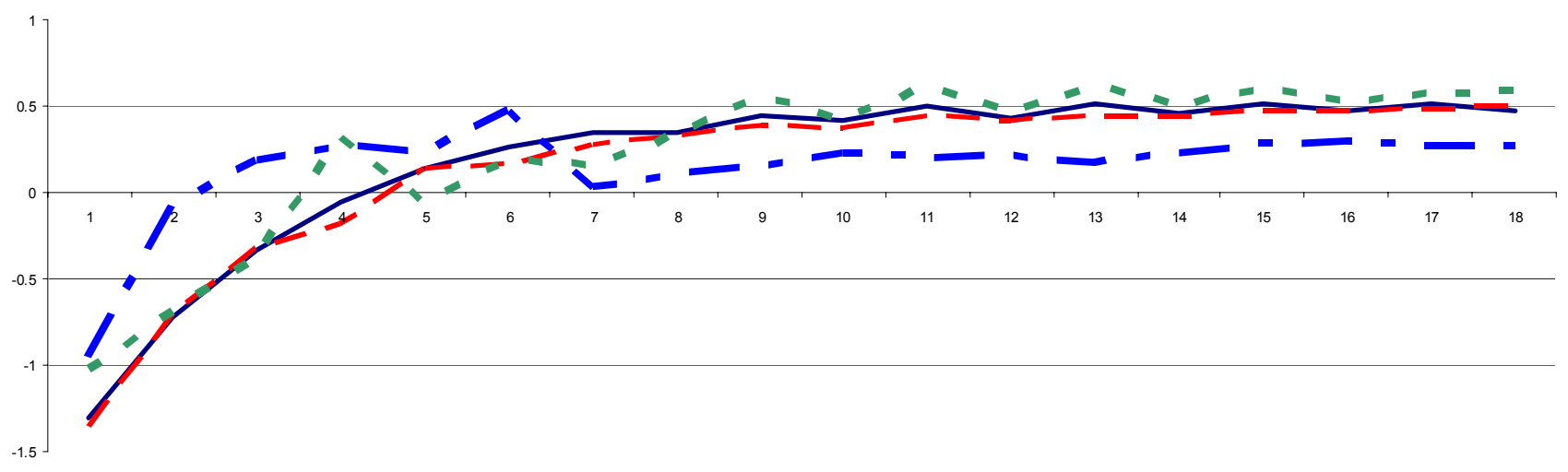

\section{Equity Price}

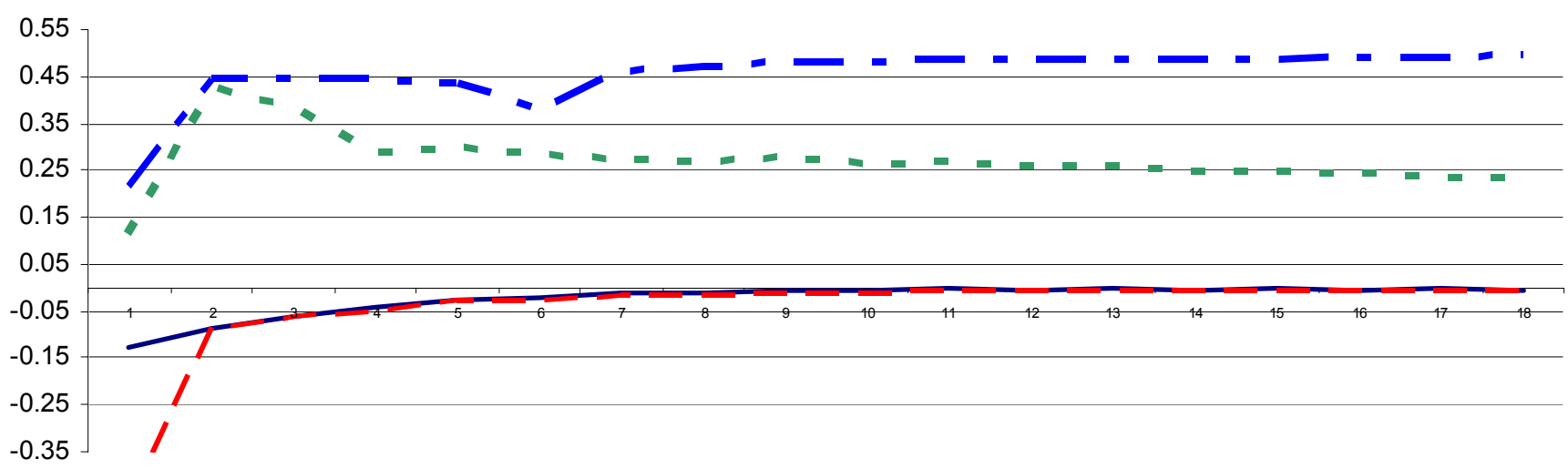

\section{Current Account-GDP Ratio}

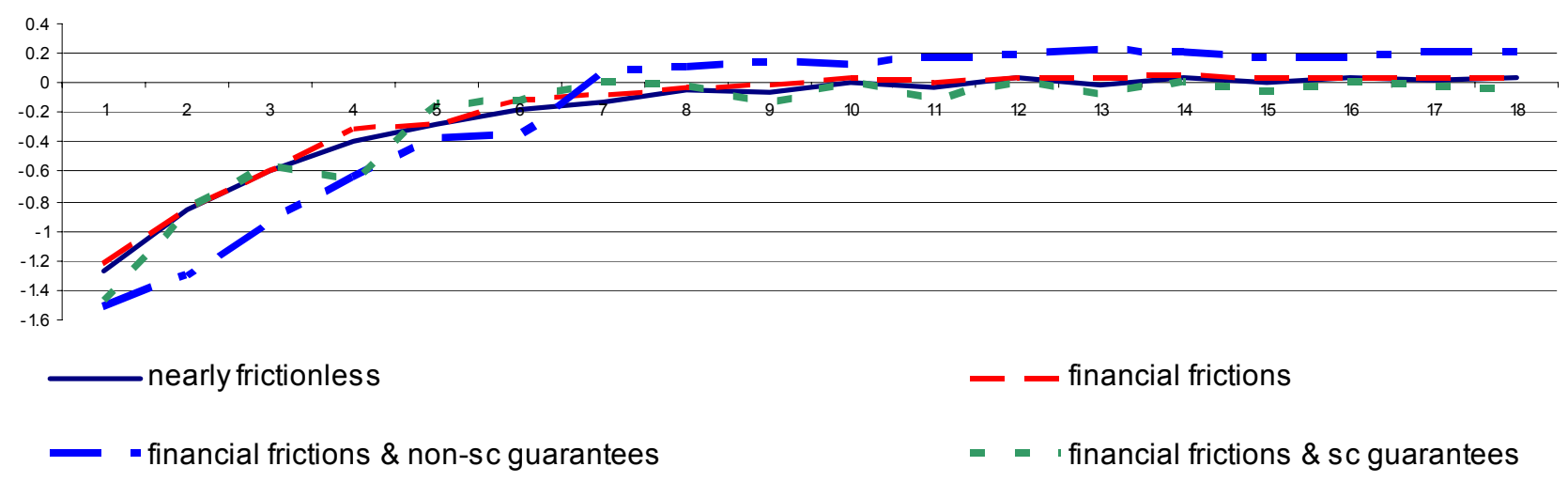

Note: forecasting functions are conditional on initial states alpha $=0.938, b=-3.38$ 
Figure 7a. Ergodic Distributions of Domestic Equity Holdings

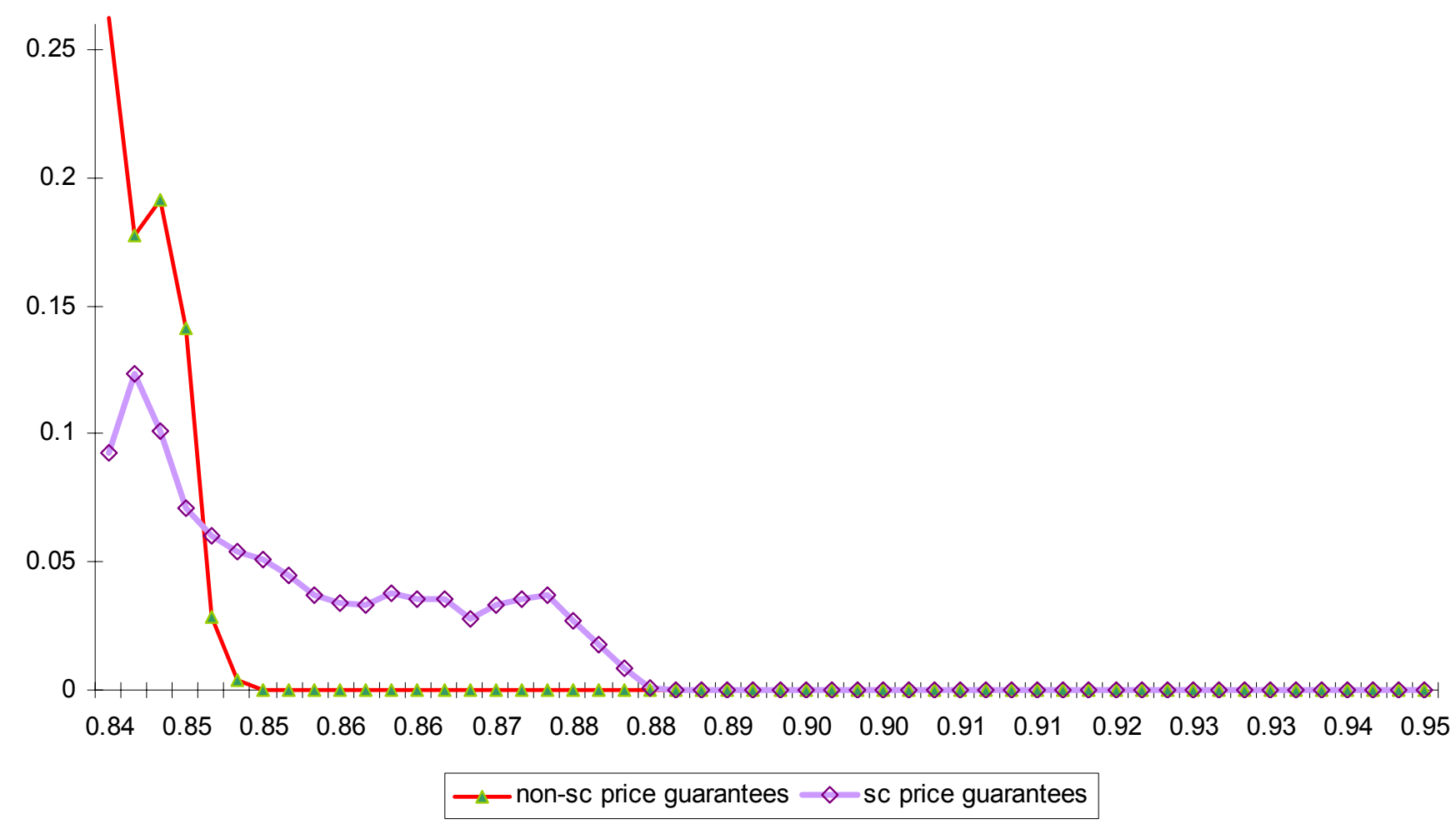


Figure 7b. Ergodic Distributions of Bonds

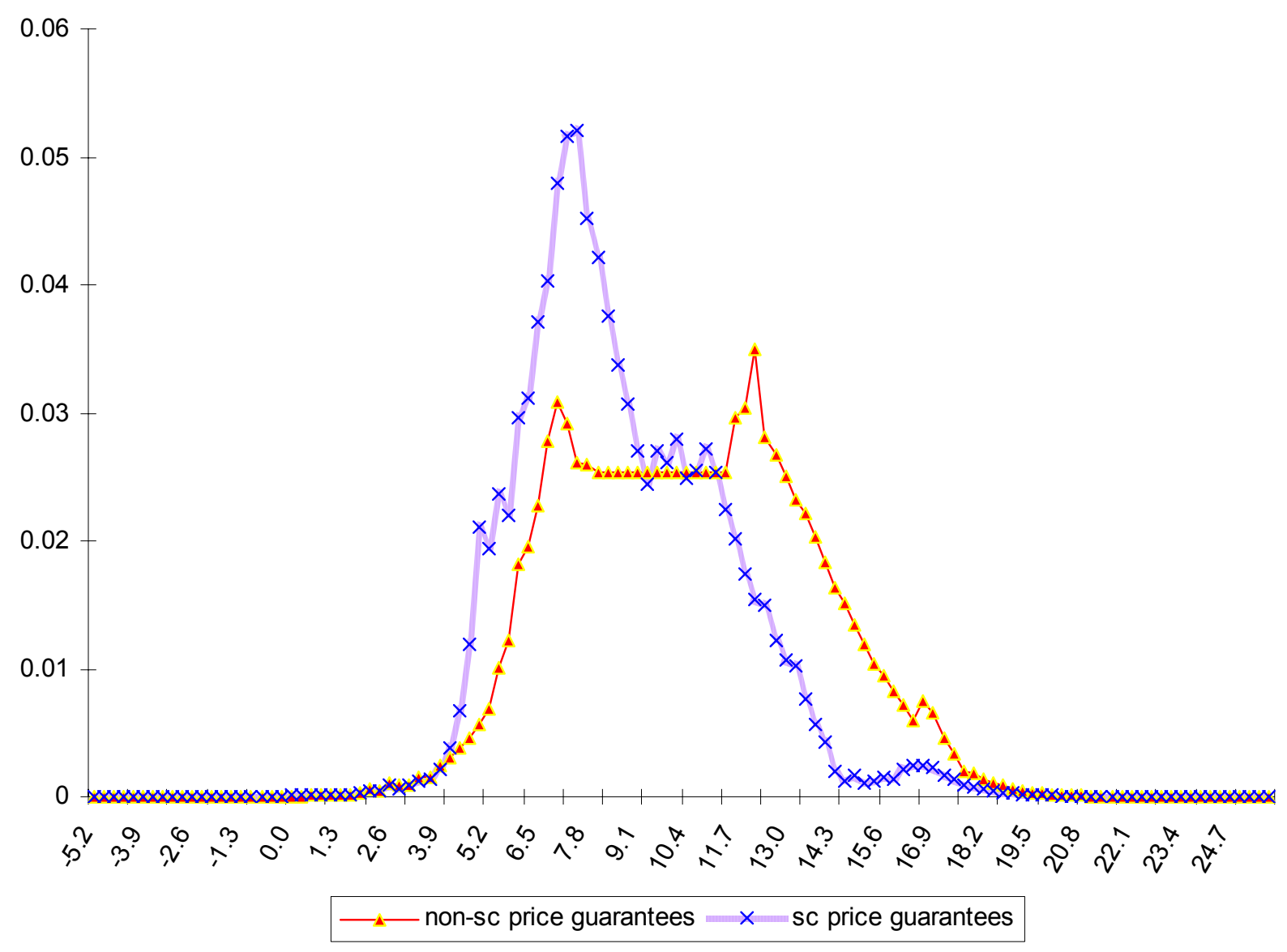


Figure 8. Equity Price in the Low Productivity State

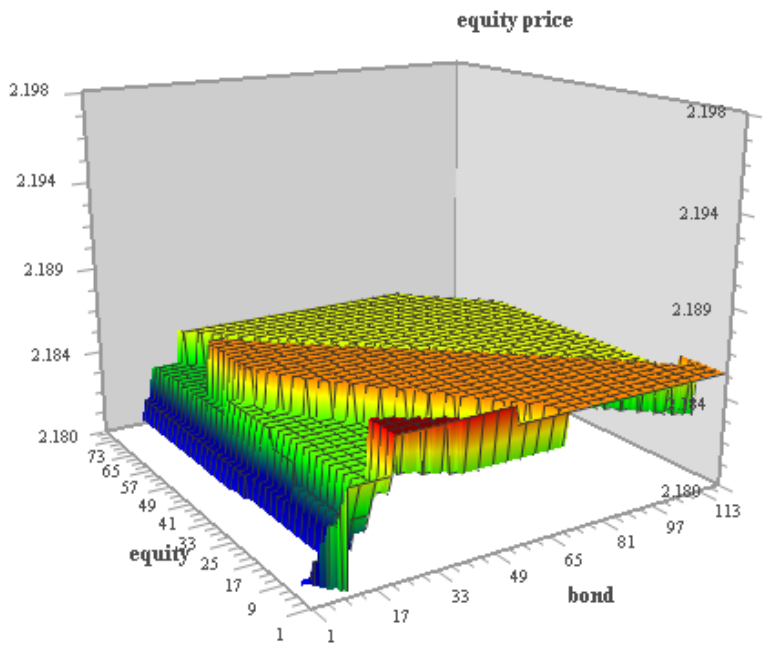

a. Economy with Financial Frictions

equity price

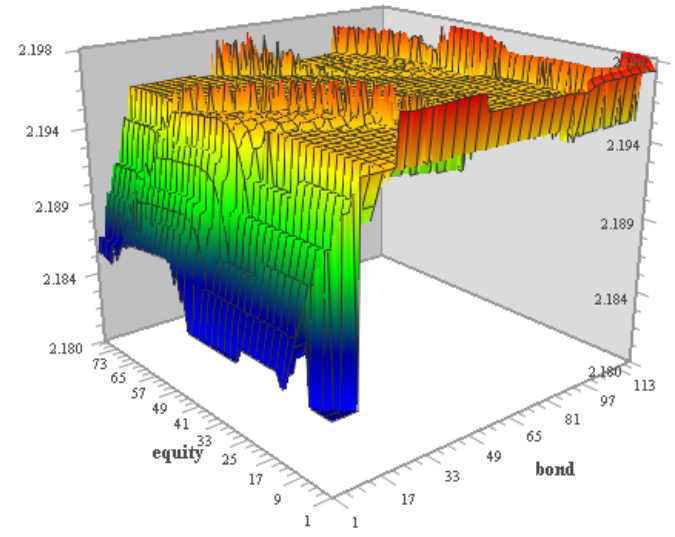

b. Economy with Financial Frictions \& Non-State Contingent Price Guarantee

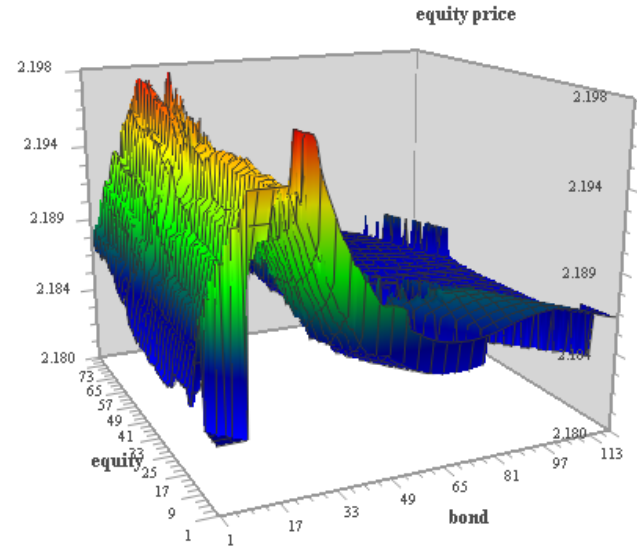

c. Economy with Financial Frictions \& State Contingent Price Guarantee 